\title{
Exosome-transmitted miR-128-3p increase chemosensitivity of oxaliplatin-resistant colorectal cancer
}

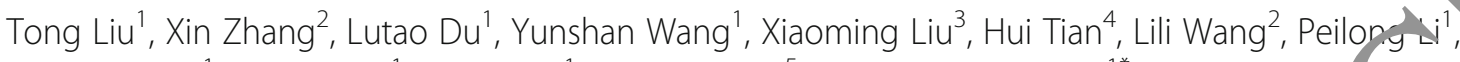
Yinghui Zhao', Weili Duan', Yujiao Xie ${ }^{1}$, Zhaowei Sun ${ }^{5}$ and Chuanxin Wang ${ }^{1 *}$

\section{Abstract}

Background: Oxaliplatin resistance is a major challenge for treatment of advanced col tal cancer (CRC). Both acquisition of epithelial-mesenchymal transition (EMT) and suppressed drug aceur lation is cancer cells contributes to development of oxaliplatin resistance. Aberrant expression of small nonco miR-128-3p, has been shown to be a key regulator in tumorigenesis and cancer development. However, its ro in the progression of CRC and oxaliplatin-resistance are largely unknown.

Methods: Oxaliplatin-resistant CRC and normal intestinal FHC cells were transfected with a miR-128-3p expression lentivirus. After transfection, FHC-derived exosomes were isolated and co-cultured with CRC cells. miR-128-3p expression in resistant CRC cells, FHC cells, and exosome was antified by quantitative real-time PCR (RT-qPCR). The mRNA and protein levels of miR-128-3p target gene resi ant CRC cells were quantified by RT-qPCR and western blot, respectively. The effects of miR-128-3p on CR were evaluated by CCK8, flow cytometry, Transw wh whe healing assays, immunofluorescence, and atomic absorption spectrophotometry. Xenograft models w used to determine whether miR-128-3p loaded exosomes can re-sensitize CRC cells to oxaliplatin in

Results: In our established stable oxalivatin-res at CRC cell lines, in vitro and vivo studies revealed miR-128-3p suppressed EMT and increased intra Eellular oxaliplatin accumulation. Importantly, our results indicated that lower miR-128-3p expression was associate with pobr oxaliplatin response in advanced human CRC patients. Moreover, data showed that miR-128-3p-transfected t. miR-128-3p delivery to oxalipla cistant cells, improving oxaliplatin response in CRC cells both in vitro and in vivo. In addition, miR-128-3p overexpresson, up-regulated E-cadherin levels and inhibited oxaliplatin-induced EMT by suppressing Bmi1 express, 1 in resistant cells. Meanwhile, it also decreased oxaliplatin efflux through suppressed expression of the dra, ar MRP5.

Conclusion: $\mathrm{C}$ results yonstrate that miR-128-3p delivery via exosomes represents a novel strategy enhancing chemosensi vity CRC through negative regulation of Bmi1 and MRP5. Moreover, miR-128-3p may be a promising diagnost and proy, stic marker for oxaliplatin-based chemotherapy.

Keywc 's.niR-218-3p, Exosome, Colorectal cancer, Chemoresistance, Epithelial-mesenchymal transition, Drug efflux

* Correspondence: cxwang@sdu.edu.cn

1 Department of Clinical Laboratory, The Second Hospital of Shandong

University, No. 247 Beiyuan Street, Jinan 250033, China

Full list of author information is available at the end of the article

(c) The Author(s). 2019 Open Access This article is distributed under the terms of the Creative Commons Attribution 4.0 International License (http://creativecommons.org/licenses/by/4.0/), which permits unrestricted use, distribution, and reproduction in any medium, provided you give appropriate credit to the original author(s) and the source, provide a link to the Creative Commons license, and indicate if changes were made. The Creative Commons Public Domain Dedication waiver (http://creativecommons.org/publicdomain/zero/1.0/) applies to the data made available in this article, unless otherwise stated. 


\section{Background}

The global incidence of colorectal cancer (CRC) is increasing; annually, more than 1.2 million new cases of CRC are diagnosed and 608,700 deaths have been attributed to this disease [1]. Oxaliplatin is one of the most commonly used chemotherapeutics following surgical resection, especially for patients with stage II and stage III disease [2]. Oxaliplatin causes intrastrand and interstrand DNA-platinum adducts and then inhibit gene transcription by segregation of transcription factors or lead to G2/ $M$ stage arrest. Moreover, the apoptotic cascade initiated by oxaliplatin is characterized by translocation of Bax to the mitochondria, cytochrome c release into the cytosol and caspase 3 activation [3]. Unfortunately, de novo and acquired oxaliplatin resistance remains a major challenge in CRC treatment [4]. The development of resistance is multi-factorial, including: up-regulation of ATP-binding cassette transporters (decreasing drug penetrance), over-active DNA damage response, enhanced antiapoptosis, and epithelial-to-mesenchymal transition (EMT) [5-7]. Therefore, elucidating the underlying mechanisms and developing effective strategies against oxaliplatin resistance are clinical priorities.

MiR-128-3p, as a microRNA, negatively correlates with MET expression in breast cancer and inhibits hepatocyte growth factor-induced cell migration by dir-ctiy targeting MET [8]. Previous microarray studies $r$ ale $d$ that miR-128-3p expression was decreased in aceno cinoma or metastatic prostate cancer when a ared $b$ normal/benign prostate tissues $[9,10]$. Subsequ studies reported that miR-128-3p expres on levels w-re an independent prognostic marker the played important roles in cell proliferation, metabolis and metastasis (lung, breast, glioblastoma, g tric cancer, and CRC) [11-15]. Although these finding $s y_{P_{1}}$ it the notion that aberrant miR-128-3p ssion is involved in several important tumorige $\mathrm{mr}$ cular pathways, the role of miR-128-3p in colip. resistance observed in advanced $\mathrm{CRC} \mathrm{r}_{1}$ ins to be clucidated.

Exosomes were scribed in as $40-150 \mathrm{~nm}$ diameter vesicles screted from several mammalian cell types [16]. Exosom fock and fuse to the membrane of tar cells, olivering exosomal surface proteins and cytoasm 17,18 . There is growing interest in utilizing exoso is as $n$ vivo delivery vehicles for miRNA as exosomes do / elicit adverse immune responses and possess low-risk for tumor formation [19]. Furthermore, exosomes loaded with therapeutic miRNAs can be manufactured in bulk by exosome producing cells in vitro thus enabling personalized treatment [20]. These findings provide rationale for designing an exosome-based therapeutic strategy for targeting oxaliplatin-resistant CRC. Here, we investigate the utility of $\mathrm{miR}-128-3 \mathrm{p}$ as a prognostic marker and its potential role in transcriptional regulation in CRC patients receiving oxaliplatin. Furthermore, we explore a novel exosome-based delivery of miR-128-3p as a therapeutic strategy for miR-128-3p-mediated chemotherapy sensitization.

\section{Methods \\ Cell culture}

All cell lines were purchased from Type Cultur olrection of the Chinese Academy of Sciences (Sha 'al, China). Oxaliplatin (Sanofi-Synthelabø, YY, US. Y) was purchased from the Second Hospitai of S dong University. Oxaliplatin-resistant cell 1 hes (HCT1),6OxR and HT29OxR) were established as $\mathrm{p}$ viously described [2, $21,22]$. For exosome co a ures, $\mathrm{g} / \mathrm{ml}$ (as determined by BCA protein assay (1 rmo Fisher Scientific, USA)) of exosomes e dded $\mathrm{t}, \mathrm{e}$ the culture medium of recipient cells $\left(5 \times 10^{6}\right)$.

\section{Clinical CRC pa. to ês}

Tissue samples wo collected prior to initiation of oxaliplatin the fromsurgical specimens or biopsies of advanced $\mathrm{ClC}$ pryents and obtained informed consent from the Scond Hospital of Shandong University $(n=$ 86, Dilu Hospital of Shandong University $(n=67)$ and Shan ng Provincial Traditional Chinese Medical Hos$1 / n=20$ ) between July 2008 and February 2018. This study was approved by the Ethics Committee of the Second Hospital of Shandong University. Patients in the oxaliplatin group were treated with at least six cycles of oxaliplatin, while patients in untreated group received no chemotherapy or stopped oxaliplatin therapy $(<21$ days) due to adverse effects. Detailed clinical characteristics of patients in training phase are listed in Additional file 1: Table S1.

Tumor response to chemotherapy was assessed as a 3-dimensional volume reduction rate or tumor response rate (radiologic assessment), and evaluated as per the Response Evaluation Criteria in Solid Tumors (RECIST) guidelines [23]. Patients with symptomatic deterioration, or appearance of new lesions, or radiologic assessment of $\geq 25 \%$ tumor regrowth in validation phase were allocated to the progressed disease (PD) group $(n=35)$ and remaining to non-PD group $(n=40)$. PFS was defined as the duration from tumor resection to PD. All patients were followed up in the clinic every 3 months (0-2 years), 6 months (2-4 years), and yearly until death or February 2018. Follow-up studies included computed tomography of the abdomen and postsurgical physical examination.

\section{Exosome purification and identification}

Exosomes were isolated from FHC cell conditioned medium by $0.22 \mu \mathrm{m}$ filtration and ultracentrifugation as we previously described [24]. Transmission electron 
microscopy (JEM-1-11 microscope, Japan) was used to image exosomes at $100 \mathrm{keV}$, and quantified by Nanosight NS300 instrument (Malvern Instruments Ltd. UK) equipped with NTA 3.0 analytical software (Malvern Instruments Ltd. UK).

\section{Immunohistochemistry}

Immunohistochemistry was done as previously reported [22]. Positive cells were counted in five random fields per slide. Interpretation of staining intensity of Bmi1 or MRP5 was made independently by two specialists, as no staining $=0$, weak staining $=1(1-25 \%)$, moderate staining $=2(26-50 \%)$, and strong staining $=3(51-100 \%)$.

\section{Quantitative real-time PCR}

Cellular and exosomal RNAs were isolated using the miRNeasy Micro Kit (QIAGEN, Valencia, CA, USA). First-strand cDNA was synthesized with random primers using High Capacity cDNA Reverse Transcription Kit (Takara, Dalian, China). qPCR was performed using Power SYBR Green (Takara, Dalian, China) on a CFX96 Real-Time PCR Detection System (Bio-Rad, USA). Data was collected and normalized to U6 levels (for cellular miR-128-3p), GAPDH (for cellular Bmi1 and MRP5 mRNA) or miR-16 (for exosomal miR-128-3p) [25]. MicroRNA primers were synthesized by RiboDro (Guangzhou, China). mRNA primers are listed j. $\mathrm{d}$ '. itional file 2: Table S3.

\section{Western blotting}

Total protein of cells or exosomes as extracter. with RIPA buffer (Sigma-Aldrich) and rantified with the BCA assay (Pierce, Rockford, IL), anc "este $n$ Blot preformed as previously described ${ }^{21}$. Protein band intensity was quantified by densitome.s, asing Image Lab software (Bio-Rad, Her s, CF, USA). All antibodies used are shown in A tio 1 file 3: Table S2.

\section{Lentiviral, plasr.. and mic. RNA mimics package and} cell transfection

Lentiviral plasmids t, lcoding miR-128-3p and negative controi re desi rned and produced by HANBIO (Shanghai hina, 'CT116OxR and HT29OxR cells were transsctec with lentivirus (pHB-U6-MCS-CMV-ZsGreenP -10 N) at a multiplicity of infection (MOI) of 20 and 15 , i éctively. The cells were then selected with $1 \mu \mathrm{g} / \mathrm{ml}$ puromycin for 3 days. pcDNA3.1 vector containing Bmi1-wt, Bmi1-mut, MRP5-wt or MRP5-mut and control were purchased from GENECHEM (Shanghai, China). miR-128-3p mimics, inhibitor and control were produced by GENECHEM (Shanghai, China). Plasmid, mimics, inhibitor and negative control were transfected using Lipofectamine2000 (Invitrogen, California, USA) according to the manufacturer's instructions.

\section{Cell viability assay}

Cells viability was determined by Cell Counting Kit 8 (Dojindo, Japan) and measured at OD450 nm with the Thermo Scientific Multiskan FC (Thermo Fisher Scientific Corporation, USA).

\section{Cell migration and invasion assay}

Cell migration was measured with Transwell a vo, briefly cancer cells $\left(2 \times 10^{4}\right.$ cells/well $)$ different groups and seeded in the apper hampers in serum-free media with or witho the Mat, gel membrane. Meanwhile the lower char ers were loaded with RPMI1640 containing $5 \%$ FL Afte uation at $37^{\circ} \mathrm{C}$, $5 \% \mathrm{CO}_{2}$ for $24 \mathrm{~h}$, the lower $\mathrm{ch}$. ber was imaged using an inverted microscore. he uppe chamber was cleaned with a cotton swas an the lower chamber was immersed and ras. $\mathrm{d}$ with $\mathrm{BS}$, fixed with $4 \%$ paraformaldehyde, sta d $1 \%$ crystal violet, washed three times with water, d imaged by Inversion Microscope (Zeiss, Gt ny).

\section{AI. I experiments}

Four eeks old male BALB/C nude mice were purchased $m$ Weitonglihua (Peking, China). HCT116OxR cells $(5) \times 10^{6}$ cells per mouse) were injected subcutaneously into the right flank of nude mice. Two weeks later, the nude mice generated tumors approximately $200 \mathrm{~mm}^{3}$ in size. Purified exosomes $(5 \mu \mathrm{g})$ or PBS was then injected intratumorally twice weekly with or without oxaliplatin treatment $\left(90 \mathrm{mg} / \mathrm{m}^{2}\right)$. The tumor size and bodyweight were measured twice per week. After seven weeks, mice were sacrificed and tumor tissues were prepared for histological examination. Tumor volume $\left(\mathrm{mm}^{3}\right)=0.5 \times$ width $^{2} \times$ length. All animal work was performed according to the Health guidelines, and protocols were approved by the Institutional Animal Care and Use Committee of Shandong University.

\section{Fluorescence assay}

PKH67 (Sigma-Aldrich, USA) $(1 \mu \mathrm{M})$ was used to label exosomes according to manufacturer's instructions. $24 \mathrm{~h}$ after PKH67-labeled exosomes were incubated with HCT116OxR, 4',6-diamidino-2-phenylindole (DAPI) (Invitrogen, USA) was used for cell nuclear staining. The slides were fluorescently visualized with a laser scanning microscope Axio-Imager-LSM800 (ZEISS, Germany). Rhodamine-conjugated secondary antibody (Cell Signaling Technology, USA) for $\gamma-\mathrm{H}_{2} \mathrm{AX}$ protein and DAPI for nuclear staining. The slides were visualized for immunofluorescence with a laser scanning microscope (Zeiss, Germany). 


\section{Electroporation of miR-128-3p into exosomes}

Gene Pulser X Electroporator (Bio-Rad, USA) was used to electroporate miR-128-3p into exosomes as previously described [22, 26, 27]. Briefly, $2 \mu \mathrm{g}$ exosomes and 400 nmol miR-128-3p mimics were mixed in $400 \mu \mathrm{l}$ of electroporation buffer at $4{ }^{\circ} \mathrm{C}$. After electroporation at $350 \mathrm{~V}$ and $150 \mu \mathrm{F}$, the mixture was incubated at $37^{\circ} \mathrm{C}$ for 30 mins to fully recover the membrane of exosomes.

\section{Luciferase reporter assay}

Cells were co-transfected with Dual-Luciferase reporter system using pmiR-REPORT ${ }^{\mathrm{TN}}$ luciferase vectors containing wild-type or mutant $3{ }^{\prime}-\mathrm{UTR}$ of Bmi1 and MRP5 and miR-128-3p mimics or miR-128-3p mimic-NC using Lipofectamine 2000 (Invitrogen, California, USA). Luciferase activity was measured by Dual-Luciferase Reporter Assay System (Beyotime Biotechnology, Shanghai, China) $48 \mathrm{~h}$ after transfection. Each group was run in triplicate in 24-well plates.

\section{Total cellular oxaliplatin and DNA-bound Pt assay}

Intracellular Pt content was quantified as described previously [28]. Briefly, after treatment with oxaliplatin $(30 \mu \mathrm{M})$, cells were lysed overnight with $0.1 \%$ triton-X-100 and $0.2 \%$ nitric acid. Cell lysates were subject to Atomic Absorption Spectrophotometry AA- 000 (SHIMADZU, Japan) and protein concentration $\mathrm{d}$ termined by BCA protein assay. DNA was isolad u DNeasy Blood \& Tissue Kits (Qiagen, Vale 1 CA) ac cording to specifications and quantified with NanoDrop spectrophotometer (Thermo Fisher Sc, ntifc, USA). The same DNA hydrolysate $y$ s used fpr Pt measurements by Atomic Absorption actrophotometry AA-6880 (SHIMADZU, Japan).

\section{Statistical analysis}

SPSS 17.0 for Win wS TRM Corporation, Armonk, NY) and GraphP.uPris (GraphPad Software, Inc., San Diego, CA, US s software were used for statistical analyses. Statistical ev ations were determined using Student's t-test (two-ailed), Kruskal-Wallis test or Spearn relit tion test. Survival rates were calculated usin the lan-Meier method and comparisons were rfo, ned us.ng the Log-rank test. The prognostic value w turun verified using the Cox proportional hazards regre on model. $P$ - value of 0.05 or less was considered as statistically significant.

\section{Results}

Acquisition of oxaliplatin resistance induces EMT and enhances drug efflux in CRC cells

To obtain oxaliplatin-resistant colorectal cancer cells, we treated HCT116 and HT29 (lowest IC50 of seven CRC cell lines to oxaliplatin, Additional file 4: Figure S1A) in vitro with escalating oxaliplatin concentrations and then grafted cells into nude mice and performed cycles of oxaliplatin treatment along with three passages in vivo. CRC cells from the third passage xenografts that acquired oxaliplatin resistance at over clinically relevant concentrations $(2 \mu \mathrm{M})$ [2] were named HCT116OyR and HT29OxR (Fig. 1a). Compared to paren 1 cells, HCT116OxR and HT29OxR cells responded $p$ 1y to oxaliplatin, as illustrated by an increased IC50 an creased drug-induced apoptosis (Fig. $\mathrm{c}$ anc Additional file 4: Figure S1B). Meanwhile, resis t cells had phenotypic changes including: los of interce, alar adhesion, spindle-cell morphology/(lo of cell/polarity), and increased pseudopodia forma n $(1-a)$ a). Furthermore, resistant cells exhibited higher igration and invasion than their parental crils ig. 1e) and enhanced motility as observed in wound hea o assay (Fig. 1f). Western blot analysis of est int cells revealed typical of changes in cells with $\mathrm{C}_{\mathrm{N}} \mathrm{v}$-induced EMT including decreased E-cadher vrotein expression but dramatically increased dherh, vimentin and fibronectin (Fig. 1g). In addition ${ }_{4}$ Ua, (itative platinum $(\mathrm{Pt})$ analysis following oxaliplatin treatment $(30 \mu \mathrm{M})$ for $24 \mathrm{~h}$ showed total In. ellular Pt and DNA-bound Pt was lower in resistant $\mathrm{t}$ in parental cells (Fig. $1 \mathrm{~h}$ and i). Immunofluoresce assay using nuclear foci of $\gamma-\mathrm{H}_{2} \mathrm{AX}$ expression as an indicator of DNA double-strand breaks revealed that oxaliplatin induced more DNA damage in parental cells than oxaliplatin-resistant cells (Fig. 1j).

\section{Decreased expression of miR-128-3p is required for CRC oxaliplatin-resistance}

Using RT-qPCR, we found all seven CRC cell lines expressed lower miR-128-3p than normal intestinal epithelial FHC cells (Additional file 4: Figure S1C). Importantly, miR-128-3p expression levels were also markedly higher expressed in HCT116 and HT29 compared with other CRC cell lines (Additional file 4: Figure S1C). Additionally, miR-128-3p expression was significantly decreased in resistant cells compared to respective parental cells (Fig. 2a). To further elucidate the role of miR-128-3p in oxaliplatin resistance, we stably overexpressed miR-128-3p using a lentiviral vector expression system (lenti-miR-128-3p) in oxaliplatin-resistant CRC cells. As expected, resistant cells transfected with lenti-miR-128-3p showed miR-128-3p levels several orders of magnitude higher than lenti-negative control (lenti-NC) transfected cells (Fig. 2b and Additional file 4: Figure S1D). Enhanced miR-128-3p expression in resistant cells reduced IC50 and increased cell apoptosis following oxaliplatin treatment (Fig. 2c, d and Additional file 4: Figure S1E-G). miR-128-3p overexpression significantly upregulated E-cadherin expression and downregulated N-cadherin, vimentin, and fibronectin expression in resistant cells (Fig. 


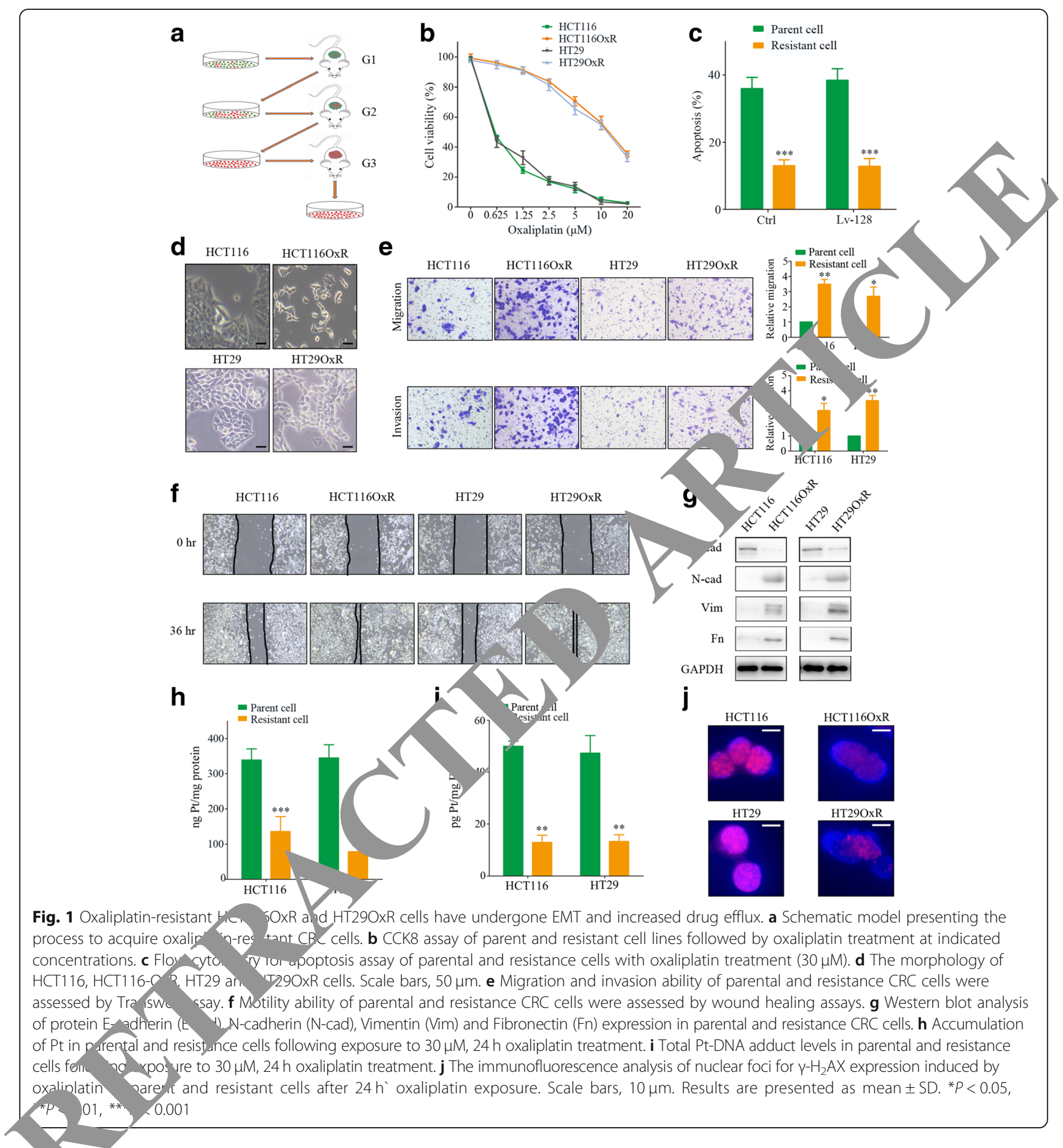

2e ydditional file 4: Figure $\mathrm{S} 1 \mathrm{H}-\mathrm{J})$. Moreover, miR-128-3p inhibited the migration, invasiveness, and motility of resistant cell lines (Fig. 2f, g Additional file 5: Figure S2A, B). Importantly, we found miR-128-3p downregulates drug efflux in CRC cells. Quantitative Pt analysis showed that following a $24 \mathrm{~h}$ oxaliplatin incubation $(30 \mu \mathrm{M})$, total intracellular Pt (Fig. $2 \mathrm{~h}$ and Additional file 5: Figure S2C) and DNA-bound Pt (Fig. 2i and Additional file 5: Figure S2D) was markedly higher in lenti-miR-128-3p transfected cells than control cells, confirming that reduced cellular Pt content is an important mechanism of oxaliplatin resistance. After $24 \mathrm{~h}$ of oxaliplatin treatment, nuclear foci of $\gamma-\mathrm{H}_{2} \mathrm{AX}$ levels in lenti-miR-128-3p cells were significantly increased, but remained low in lenti-NC cells (Fig. $2 \mathrm{j}$ and Additional file 5: Figure S2E). Finally, to determine whether miR-128-3p sensitizes CRC cells to chemotherapeutic agents in vivo, lenti-miR-128-3p transfected HCT116OxR cells were 


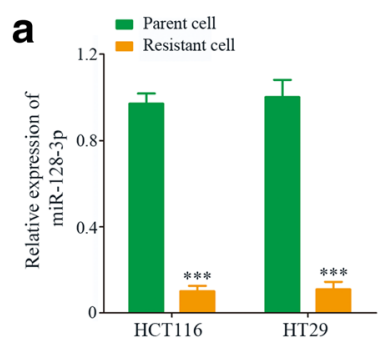

d

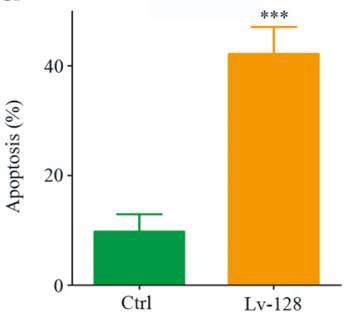

e

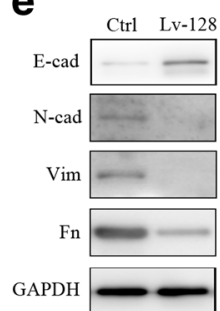

g
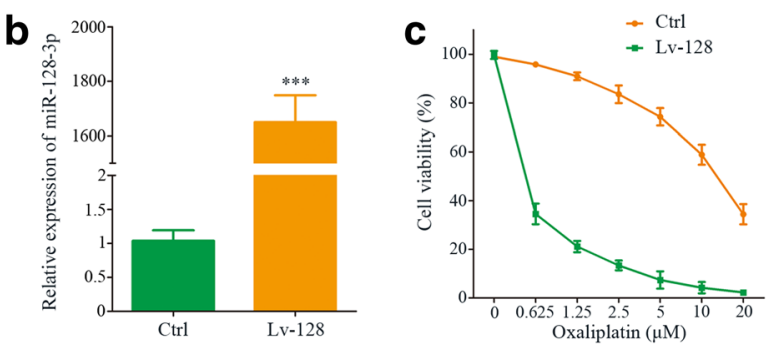

f
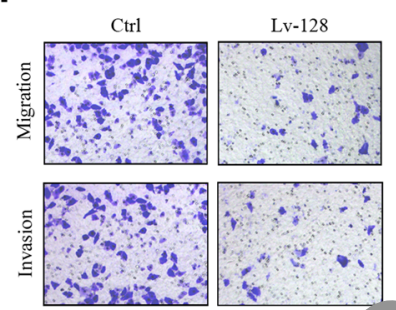

h

i
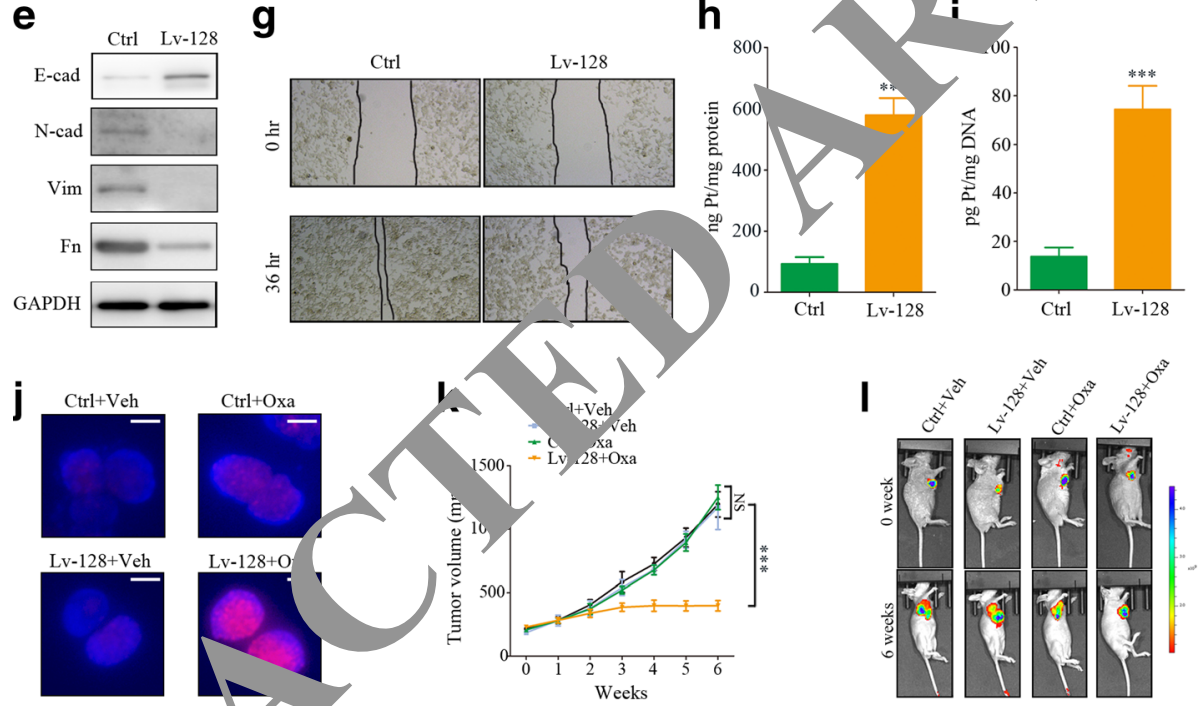

Fig. 2 miR-128-3p expression $\quad R C$ cel lines and its effect on oxaliplatin resistance. a RT-qPCR assay was performed to detect the miR-128-3p expression in parent and sistal CRC ce ' $\mathrm{S}$. b RT-qPCR assay was performed to detect the miR-128-3p expression in HCT1160xR cells transfected with lenti-miR-128-3p (Lv-, negative control (Ctrl). c CCK8 assay of HCT1160xR cells transfected with Lv-128 and Ctrl with oxaliplatin treatment at indicated conce, tions. d Flow cytometry for apoptosis assay of HCT1160xR cells transfected with Lv-128 and Ctrl with oxaliplatin treatment (30 $\mu \mathrm{M}$. estern blo analysis of E-cad, N-cad, Vim, and Fn expression in HCT1160xR cells transfected with Lv-128 and Ctrl. f Migration and invasion abnity of T160xR cells transfected with Lv-128 and Ctrl were assessed by Transwell assay. $\mathbf{g}$ Motility ability of HCT1160xR cells transfected' with Lv-128 à Ctrl were assessed by wound healing assays. h Accumulation of Pt in HCT116OxR cells transfected with Lv-128 and Ctrl followir sxp sure to $30 \mu \mathrm{M}, 24 \mathrm{~h}$ oxaliplatin treatment. i Total Pt-DNA adduct levels in HCT116OxR cells transfected with Lv-128 and Ctrl following exposure $2 \mu \mathrm{M}, 7$ th oxaliplatin treatment. $\mathbf{j}$ The immunofluorescence analysis of nuclear foci for $\mathrm{y}^{-} \mathrm{H}_{2} \mathrm{AX}$ expression in $\mathrm{HCT} 1160 \mathrm{Ox}$ cells transfected 128 after $24 \mathrm{~h}$ oxaliplatin exposure $(30 \mu \mathrm{M})$. Scale bars, $10 \mu \mathrm{m}$. Subcutaneous xenograft assay of miR-128-3p-overexpressing and control 'HCT1) $50 x R$ cen $15 \times 10^{6}$ cells) in nude mice with vehicle (veh) or oxaliplatin $\left(O x a, 90 \mathrm{mg} / \mathrm{m}^{2}\right)$ treatment. Tumor volume of xenograft models were

sureu . om day 0 to day 42 . Volumes of tumors $(k)$ and representative bioluminescent images $(I)$ are shown $(n=5)$. Results are presented as mean $\pm S$.

implanted subcutaneously into nude mice then treated with oxaliplatin. Our data indicated that miR-128-3p overexpression significantly decreased oxaliplatin resistance in HCT116OxR xenografts in vivo (Fig. 2k and l). These data support our in vitro findings, indicating that miR-128-3p ameliorates oxaliplatin-resistant CRC in vitro and in vivo. Collectively, these results demonstrate that decreased
miR-128-3p expression is indispensable for oxaliplatin resistance in CRC cells.

\section{miR-128-3p levels in tumor tissues correlate with oxaliplatin response in CRC patients}

As we observed miR-128-3p was substantially downregulated in both HCT116OxR and HT29OxR cells compared 
to parental cells, we felt it was important to establish clinical relevance in human CRC. Therefore, we analyzed miR-128-3p tissue levels in an independent large-scale sample set using RT-qPCR. Kruskal-Wallis test analysis indicated miR-128-3p expression levels in tissues were significantly lower in patients suffering from tumor relapse after oxaliplatin therapy $(0.065 ; 0.033-0.088)$ compared with patients that responded well to neoadjuvant oxaliplatin therapy $(0.169 ; 0.101-0.237)$ or who were therapy naive $(0.204 ; 0.086-0.277)$ (all at $P<0.001$ ). Compared with noncancerous tissues (1.014; 0.937-1.904), miR-128-3p expression levels were also markedly reduced in CRC tissues $(P<0.001$, Fig. 3a and Additional file 1: Figure Table S1). We then explored the predictive value of miR-128-3p levels for oxaliplatin response in CRC patients. Expression levels of miR-128-3p were downregulated in patients with progressive disease (PD) during oxaliplatin therapy than those without PD (non-PD) (Fig. 3b). Receiver operating characteristic (ROC) curve analyses showed that miR-128-3p has a strong capability for discriminating non-PD patients from PD patients with an area under ROC curve (AUC) value of 0.868 (95\% CI: $0.770-0.935$, Fig. 3c). At an optimal cut-off value of 0.227 , the sensitivity and specificity were 65.0 and $91.4 \%$ Furthermore, the median miR-128-3p expression lev ( (0.269) was used to categorize CRC patients into two oups high-level $(n=61)$ and low-level $(n=61)$. Similar c al characteristics between control and oxa. tin tre thent groups were observed before treatmalc As iations between miR-128-3p and pathologies of CRC pat ents in validation phase are summarized in Iditional file 2: Figure Table S3. Although Kaplan - ier val analysis indicated higher miR-128-3r expres $n$ was associated with longer progression-fre vival (.FS) in CRC patients, there is limited benefit $3 \mathrm{~d}$ ). Patients with low miR-128-3p exores, on had a poor PFS in oxaliplatin

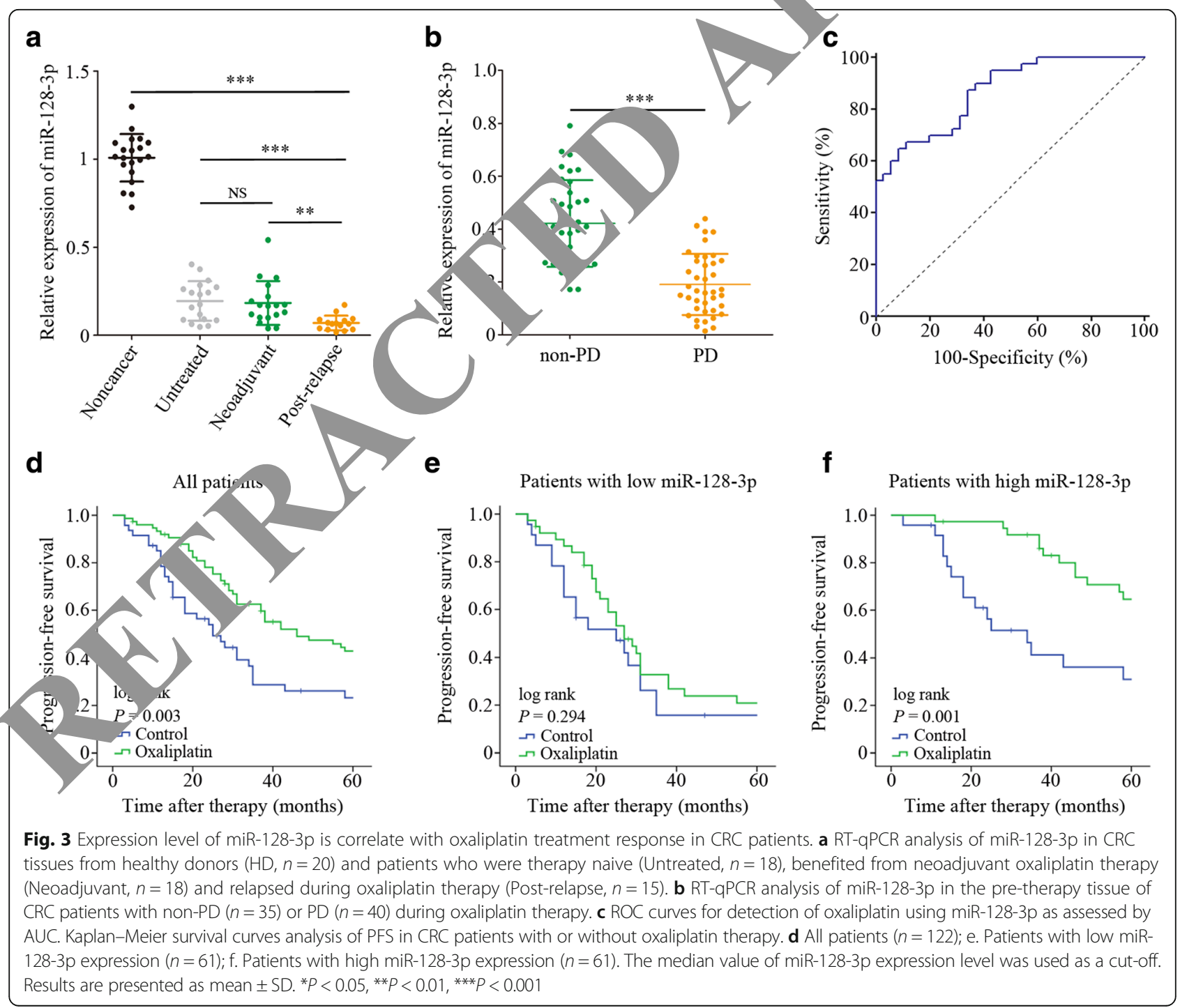


treatment (Fig. 3e). Conversely, the high miR-128-3p expression group exhibited a superior PFS after receiving oxaliplatin compared to the control group (Fig. 3f). Cox regression univariate and multivariate analysis revealed that oxaliplatin therapy correlated with improved PFS of CRC patients with high miR-128-3p expression (Table 1). Thus, miR-128-3p could serve as an independent predictor for oxaliplatin response in CRC patients.

miR-128-3p is highly expressed and secreted by miR-128-3p transfected FHC cells and can be transferred to resistant $\mathrm{CRC}$ cells via exosome secretion

Previous studies suggest miRNAs can be packaged into exosomes and functionally delivered to target cells to directly modulate target mRNAs [29]. Herein, we transfected FHC cells with lenti-miR-128-3p or lenti-NC. Subsequently, extracellular exosomes were isolated from the FHC supernatant after $48 \mathrm{~h}$ and identified with electron microscopy by their typical cup-shaped morphology ( 40 to $120 \mathrm{~nm}$ ) and by exosomal markers (CD63 + CD9 + GM130-) (Fig. 4a and b). The miR-128-3p expression was markedly higher in lenti-miR-128-3p FHC cells (FHC-128) and their exosomes (128-exo) than in lenti-NC FHC (FHC-NC) and associated exosomes (NC-exo) (Additional file $\mathrm{Fi}_{\mathrm{i}}$ ure S2F and Fig. 4c). We then determined whe
miR-128-3p was indeed present within exosomes. As expected, miR-128-3p expression in culture medium was unchanged upon RNase A treatment but significantly decreased when treated with RNase A and Triton X-100 simultaneously (Fig. 4d), suggesting that released miR-128-3p was protected by doubl layer membrane instead of being directly release? When 128-exo (labeled with membrane phosphor, dye PKH67) were incubated with HCT116OxR celt necipient cells exhibited high uptake efn ncy, a neasured by laser scanning confocal picrosc (D/g. 4e). After $24 \mathrm{~h}$ ' incubation, $>80 \%$ o recipient cells were positive for PKH67 fluorescen (Additional file 6: Figure S3A), suggesting that 8 - $t$. effectively internalized by HCT1 $160 x$ kells. 128-exo coincubations increase d R-128- $\mathrm{p}$ levels in resistant cells nearly 350-fold, wi NC-exo did not affect miR-128-3p expre on levels (Fig. 4f and Additional file 6: Figure $\mathrm{B}$, reover, prolonged incubation caused a corresp ding increase in miR-128-3p levels in HCT1 1 R cels (Fig. 4g). Additionally, actinomycin D (RNA/Py,ymerase II inhibitor) did not significantly altre miR-128-3p levels, excluding the po. bility of endogenous induction of miR-128-3p in recip nt resistant cells (Fig. 4h). Taken together, these a)demonstrate FHC-128 cells efficiently secrete ex osomes containing miR-128-3p that can be directly cransferred to HCT116OxR cells.

Table 1 Univariate and multivariate analysis fil actors à ciated

\begin{tabular}{|c|c|c|c|c|}
\hline \multirow[t]{2}{*}{ Variables } & \multicolumn{2}{|l|}{ Low miR-128 $(n=61)$} & \multicolumn{2}{|l|}{ High miR-128 $(n=61)$} \\
\hline & Harzard ratio $(95 \% \mathrm{Cl})$ & $P$ value & Harzard ratio $(95 \% \mathrm{Cl})$ & $P$ value \\
\hline \multicolumn{5}{|l|}{ Univariate analysis } \\
\hline Oxaliplatin vs control & $0.734(0.405-1.330)$ & 0.308 & $0.295(0.137-0.637)$ & $0.002^{*}$ \\
\hline Gender (ma & $1.310(0.732-2.345)$ & 0.363 & $1.190(0.559-2.534)$ & 0.652 \\
\hline Age $(>6$ & 1.197(0.670-2.141) & 0.544 & $1.215(0.571-2.586)$ & 0.613 \\
\hline Tumor siz & $1.411(0.781-2.550)$ & 0.253 & $0.720(0.315-1.645)$ & 0.436 \\
\hline & $0.618(0.340-1.121)$ & 0.113 & $1.293(0.600-2.789)$ & 0.512 \\
\hline Moderate vs Poor) & $0.890(0.492-1.611)$ & 0.701 & $0.802(0.372-1.729)$ & 0.573 \\
\hline & $0.559(0.280-1.118)$ & 0.100 & $1.259(0.435-3.646)$ & 0.671 \\
\hline & $1.117(0.587-2.124)$ & 0.736 & $2.203(0.883-5.498)$ & 0.090 \\
\hline trol & & & $0.311(0.140-0.688)$ & $0.004^{*}$ \\
\hline Gencer (male vs female) & & & $0.947(0.391-2.293)$ & 0.905 \\
\hline Age ( $>60$ vs $\leq 60$ years) & & & 0.898(0.385-2.093) & 0.803 \\
\hline Tumor size $(\leq 4$ vs $>4 \mathrm{~cm})$ & & & $0.805(0.285-2.276)$ & 0.683 \\
\hline Tumor location (Rectum vs colon) & & & $0.913(0.315-2.650)$ & 0.868 \\
\hline Tumor differentiation (Well vs Moderate/Poor) & & & $1.210(0.412-3.551)$ & 0.729 \\
\hline TNM stage (II vs III/IV) & & & $1.046(0.306-3.576)$ & 0.943 \\
\hline Distant metastasis (NO vs YES) & & & $2.014(0.484-8.380)$ & 0.336 \\
\hline
\end{tabular}




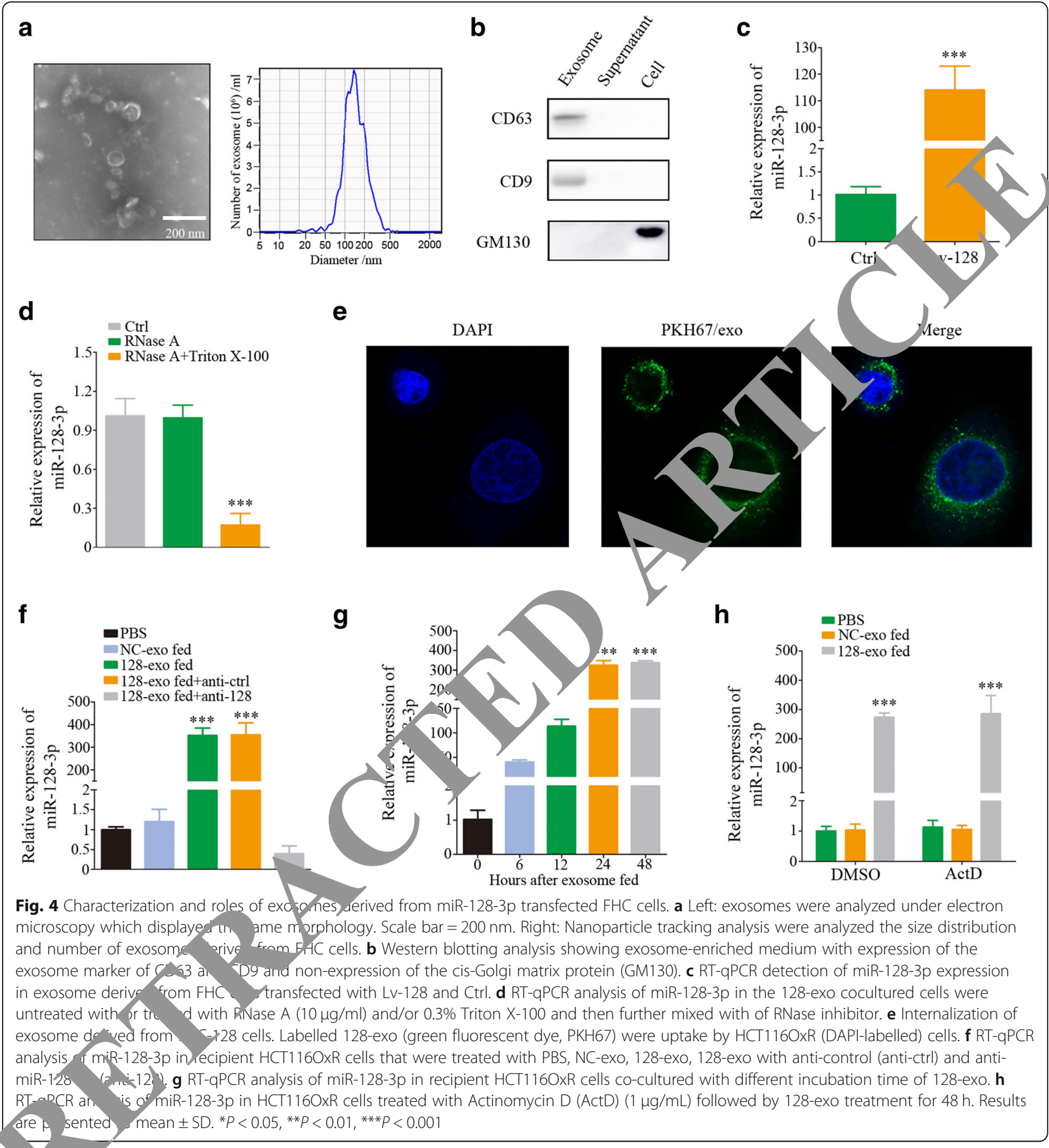

Exos e-mediated transfer of miR-128-3p reversed oxaliplatin resistance through altering target gene expression

We next investigated whether exosome-transferred miR128-3p could ameliorate chemosensitivity in resistant cells. In a cell viability and Annexin V/PI apoptosis assay, oxaliplatin-resistant cells incubated directly with 128-exo displayed elevated oxaliplatin sensitivity (Fig. 5a, $\mathrm{b}$ and Additional file 6: Figure S3C-E) which was abolished by transfecting recipient cells with a miR-128-3p inhibitor (anti-128). To exclude other factors in exosomes besides miR-128-3p in mediating oxaliplatin sensitivity, we electroporated miR-128-3p mimics directly into exosomes and it did not affect the physical properties of the exosomes (Additional file 6: Figure S3F). Indeed, HCT116OxR cells co-cultured with exosomes successfully up-took miR-128-3p mimics (Additional file 6: Figure S3G) and also exhibited increased 

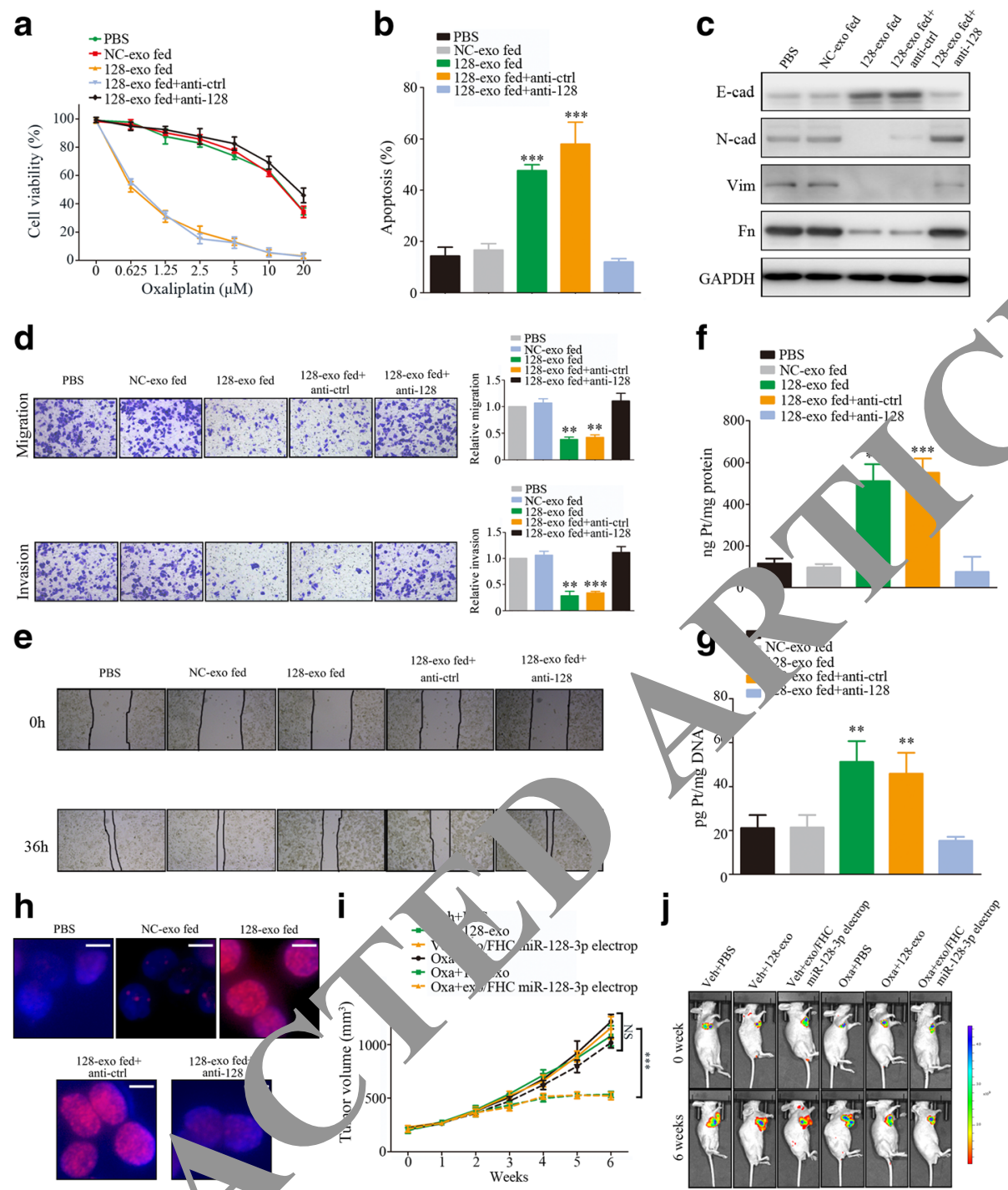

Fig. 5 Intercellular transfer of -128-3, by 128-Exo sensitizes CRC cells to oxaliplatin agents. a CCK8 assay of HCT1160xR cells pre-incubated with indicated factors for $\mathrm{h}$ fo owed b/Oxaliplatin treatment at indicated concentrations. b Flow cytometry for apoptosis assay of HCT1160xR cells pre-incubated with in frer for $48 \mathrm{~h}$ followed by oxaliplatin treatment $(30 \mu \mathrm{M})$ for $24 \mathrm{~h}$. c Western blot analysis of protein E-cad, $\mathrm{N}$ cad, Vim, and Fn ev ression il T) 160xR cells after incubated with indicated factors. d Migration and invasion ability of HCT1160xR cells after incubated with ia ed factors, or $48 \mathrm{~h}$ were assessed by Transwell assays. e Motility ability of HCT1160xR cells after incubated with indicated factors for $48 \mathrm{~h}$ were a racd by wound healing assays. $\mathrm{f}$ Accumulation of Pt in HCT116OxR cells after incubated with indicated factors for $48 \mathrm{~h}$ following exposure to $30, M, 24 \mathrm{~h}$ oxaliplatin treatment. $\mathbf{g}$ Total Pt-DNA adduct levels in HCT1160xR cells after incubated with indicated factors for 48 lov ing exposure to $30 \mu \mathrm{M}, 24 \mathrm{~h}$ oxaliplatin treatment. $\mathbf{h}$ Immunofluorescence analysis of nuclear foci for $\mathrm{Y}-\mathrm{H}_{2} \mathrm{AX}$ expression $\mathrm{HCT} 116 \mathrm{OxR}$ cells incub I with indicated factors for $48 \mathrm{~h}$ followed by $24 \mathrm{~h}$ ' oxaliplatin exposure $(30 \mu \mathrm{M})$. Scale bars, $10 \mu \mathrm{m}$. i Subcutaneous xenograft assay $1160 x$, Is $\left(5 \times 10^{6}\right.$ cells $)$ in nude mice with intratumoral injection of PBS, 128-exo and exo/FHC miR-128-3p electrop in nude mice with ehic ox oxahplatin $\left(90 \mathrm{mg} / \mathrm{m}^{2}\right)$ treatment. Tumor volume of xenograft models were measured from day 0 to day 42 . Volumes of tumors (i) and . esentarive bioluminescent images (j) are shown ( $n=5$ per group). Results are presented as mean \pm SD. ${ }^{*} P<0.05,{ }^{* *} P<0.01,{ }^{* * *} P<0.001$.

oxaliplatin sensitivity (Additional file 6: Figure S3H). Importantly, incubated with 128-exo suppressed EMT, as characterized by upregulation of epithelial markers and downregulation of mesenchymal markers in resistant cells, while anti-128 blocked this progression (Fig. 5c and Additional file 7: Figure S4A-C). Moreover, 128-exo suppressed migration and invasion of resistant CRC cells across Transwell filters (Fig. 5d and Additional file 7: Figure S4D). And wound healing assays further showed that 128-exo suppressed motility in resistant cells (Fig. 5e and Additional file 7: Figure S4E). Both these affects were abolished with addition of anti-128. Using atomic absorption spectroscopy (AAS), we found that the total intracellular Pt and DNA-bound Pt levels in resistant 
cells was significantly increased when treated with 128-exo (Fig. 5f, g Additional file 7: Figure S4F, G). At 24 ' ' post oxaliplatin treatment, the nuclear foci of $\gamma-\mathrm{H}_{2} \mathrm{AX}$ levels in the control group remained low but were significantly increased in the 128-exo co-culture group (Fig. 5h and Additional file 8: Figure S5A). Additionally, we found that the restored oxaliplatin sensitivity in recipient cells was sustained for at least 10 days following removal of 128-exo (Additional file 8: Figure S5B). Importantly, intra-tumor injection of miR-128-3p exosomes restored oxaliplatin response in resistant cells in vivo (Fig. $5 \mathrm{i}$ and $\mathrm{j}$ ) and was accompanied by an increase in tumor miR-128-3p levels (Additional file 8: Figure S5C). Furthermore, miR-128-3p mimic-loaded exosomes were also effective. Therefore, these results confirm that miR-128-3p overexpression through 128-exo reverses oxaliplatin resistance in CRC cells in vitro and vivo.

\section{Bmi1 and MRP5 are responsible for miR-128-3p-mediated oxaliplatin resistance}

We further sought to identify the mediators of miR-128-3p-driven oxaliplatin resistance. Previous reports suggest interactions of Bmil/E-cadherin and ATP-dependent glutathione S-conjugate export pump (e.g. MRP5) are important regulators [30-32]. To identify the potential pathway, we performed bioinformatic analysis with TargetScan and Miranda. This reve? th $3{ }^{`}$-UTR of Bmi1 and MRP5 contain a predicte 4 bin o site for miR-128-3p (Fig. 6a). Furthermore, , found a, inverse correlation between miR-128-3p levels a Bmi1 mRNA $(\mathrm{r}=-0.445, P<0.001)$ or MRP5 expl ¿ssion mRNA $(\mathrm{r}=-0.538, P<0.001)$ in $C \mathrm{C}$ tissues (Fig. $6 \mathrm{~b}$ and $\mathrm{c}$ ). To verify whether Bmil and $\mathrm{N} 5 \mathrm{ar}$ - direct targets of miR-128-3p, Dual-Lu corase reporter system with pmiR-REPORT ${ }^{\mathrm{Tm}}$ lucifer: se ctors containing wild-type or mutant 3 TR or Bmil and MRP5 was used. Co-transfectio of miR-1/28-3p mimics significantly suppressed the iferase activity of the reporter containing wila pe $3^{\wedge}-\iota, R$, but not the mutant reporter (Additiona 9: Figure S6A and B). These data reveal that Bmi1 and MRP5 are direct functional targets of mik- Q PT-qPCR and western blot assay indicat that B nil and MRP5 mRNA and protein levels rere ower an miR-128-3p overexpressing cells comp. a controls (Additional file 9: Figure S6C-E). To furt. Validate these results, we employed a 'rescue' experiment by transfecting pcDNA3.1 vector carrying Bmi1 or MRP5 expression cassette with wild or mutated type seed sequences for miR-128-3p (Bmi-wt/Bmil-mut or MRP5-wt/MRP5-mut) at its 3'-UTR into lenti-miR-128-3p transfected resistant cells. A cell viability and apoptosis assay indicated that only transfection of resistant cells with Bmi1-mut or MRP5-mut developed a resistant phenotype, while co-transfection with a
Bmi1-wt or MRP5-wt did not and were silenced by miR-128-3p (Fig. 6d, e and Additional file 9: Figure S6F$\mathrm{H})$. Western blots assay demonstrated that transfecting resistant cells with Bmi1-mut permitted Bmi1, $\mathrm{N}$-cadherin, vimentin, and fibronectin protein expression and suppressed E-cadherin protein expression, while transfection with Bmi1-wt was silenced by mi $<-128-3 p$ and could not recover EMT (Fig. $6 \mathrm{f}$ and Addition 10 Figure S7A). Moreover, 'rescuing' Bmi1-mut express. in the presence of miR-128-3p enhanced invasi $n$ and migration of HCT116OxR cells (Fig og, h a Ad ditional file 10: Figure S7B, C). Collectively these data saggest that miR-128-3p regulates chemothe vy-induced EMT of CRC cells by targeting Bmir. su. sought to identify the drug efflux mech nism o iR-128-3p-driven oxaliplatin resistance. Wf st blottino revealed a significant increase in MRP5 protein the MRP5-mut transfected cells, as MRP5 pro ins in the mock, control groups or cells transfecte 'it' 5-wt remained unchanged (Fig. 6i and Additional 10: Figure S7D). Importantly, transfected $\mathrm{M}$ mut significantly decreased the total intracellular Planc DNA-bound $\mathrm{Pt}$ in lenti-miR-128-3p transfected HCT116OxR cells compared with the cells tra ected with mock, control and MRP5-wt (Fig. 6j, k and Iditional file 10: Figure S7E, F). The nuclear foci of , $\mathrm{X}$ expression levels revealed that oxaliplatin induced less DNA damage at 24 h in MRP5-mut group than other groups in lenti-miR-128-3p transfected resistant cell lines (Fig. 61 and Additional file 10: Figure S7G). In addition, treatment with 128-exo significantly decreased Bmi1 and MRP5 expression at protein levels in resistant cell lines, and miR-128-3p inhibitor in recipient cells disrupted this effect (Fig. $6 \mathrm{~m}$ and Additional file 10: Figure $\mathrm{S} 7 \mathrm{H})$. Furthermore, forced miR-128-3p expression through intra-tumor injection of exosomes restored oxaliplatin response in resistant cells through blocked Bmi1 and MRP5 associated signaling in vivo (Fig. 6n). These findings indicate that 128-exo potentially facilitates oxaliplatin sensitivity in CRC cells by negatively regulating Bmi1 and MRP5 expression, two genes involved in oxaliplatin-induced EMT and drug efflux respectively.

\section{Discussion}

Presently, advanced CRC patients who develop oxaliplatin resistance have limited therapeutic options. Hence, it is necessary to investigate the biological basis of oxaliplatin resistance and identify novel therapeutic targets and prevention strategies for oxaliplatin resistance. This study identified miR-128-3p as an important antitumor microRNA and inhibitor of tumor progression. miR-128-3p is downregulated in oxaliplatin-resistant CRC and functionally required to the suppress the drug resistant phenotype. miR-128-3p overexpression re-sensitizes oxaliplatin 

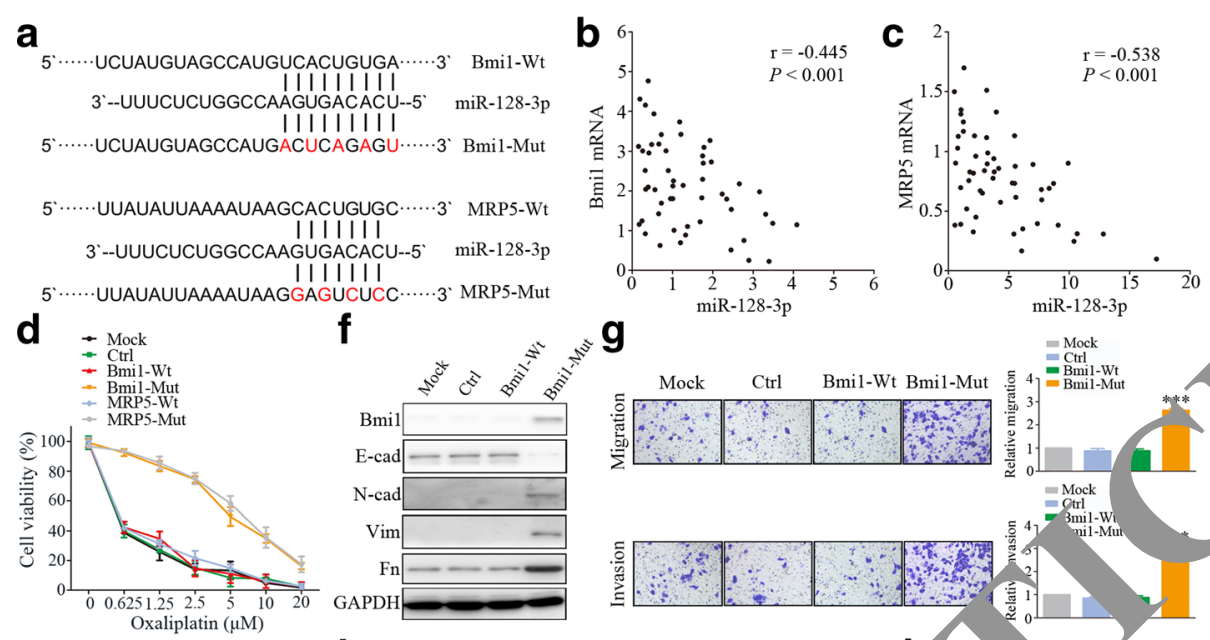

g
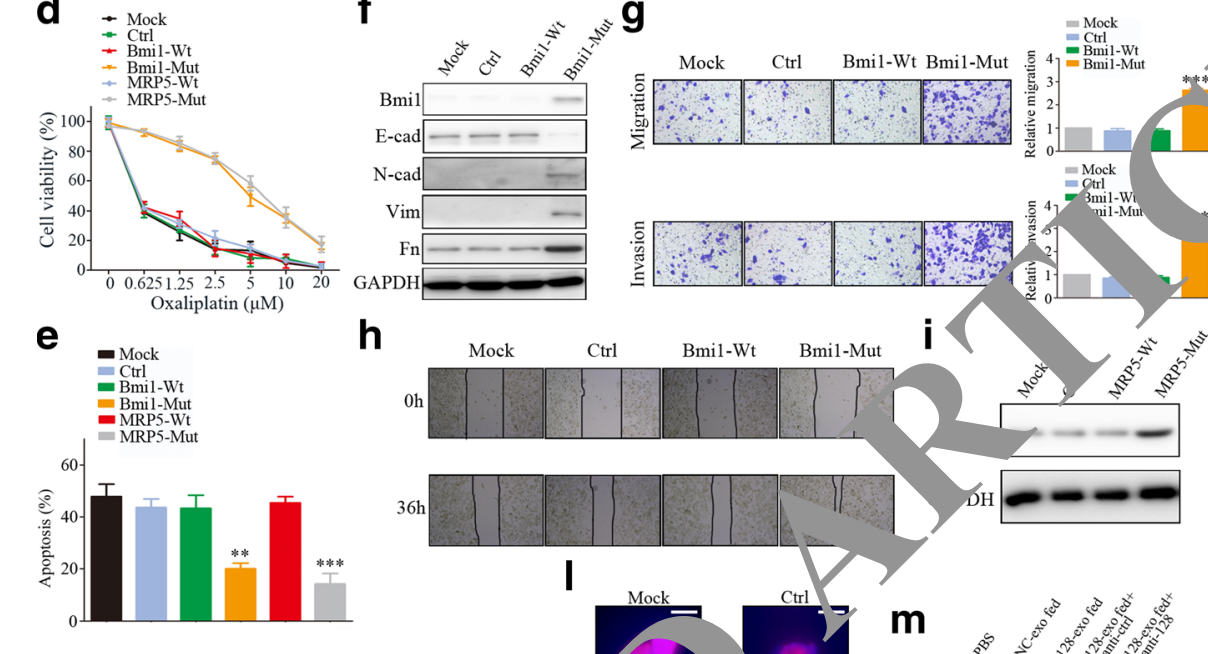

(
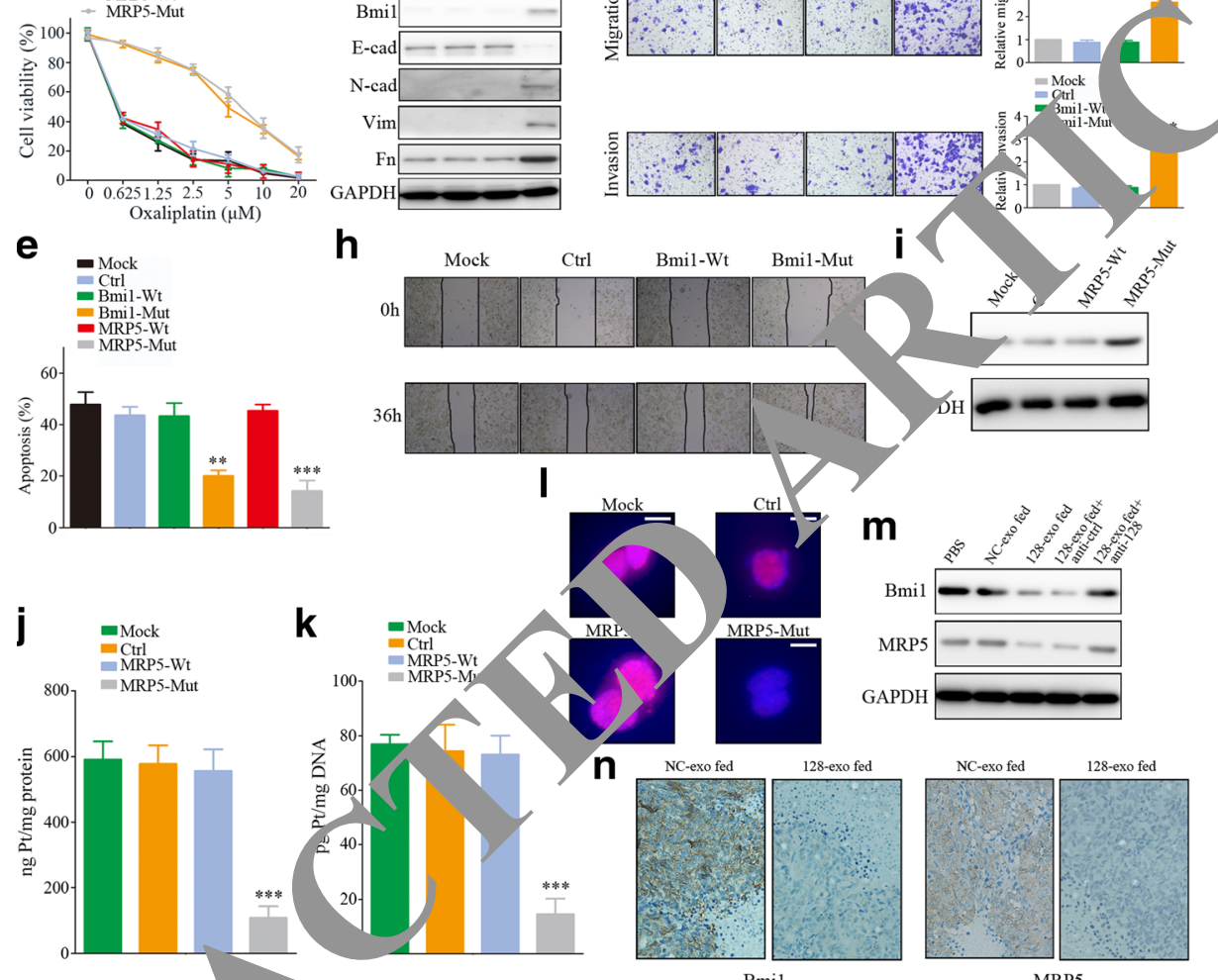

Bmil

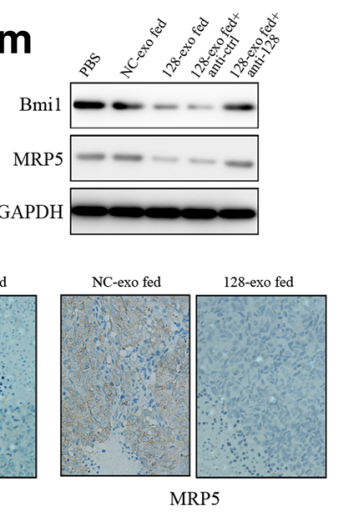

Fig. 6 Exosomes containing miR-128-3A schsiv_ed CRC cells to oxaliplatin by targeting to Bmi1 and MRP5. a Illustration of the putative predicted miR-128-3p binding site in une $\mathrm{i} 1$ and MRP5 mRNA 3'-UTR region. $\mathbf{b}$ Spearman's correlation analysis between Bmi1 mRNA levels and miR-128$3 p$ levels in CRC tissues, near h'c conelation analysis between MRP5 mRNA levels and miR-128-3p levels in CRC tissues. $\mathbf{d}$ CCK8 assay of Lv128 transfected HCT1 $\mathrm{OXK}$. $\mathrm{S}$ in umerent conditions followed by oxaliplatin treatment at indicated concentrations. e Flow cytometry for apoptosis assay of -128 trans HCT1160xR cells in different conditions followed by oxaliplatin treatment ( $30 \mu \mathrm{M})$ for $24 \mathrm{~h}$. f Western blot analysis of prot in b-cad, A-cad, Vim, and Fn expression of LV-128 transfected HCT1160xR cells in different conditions. g Migration and

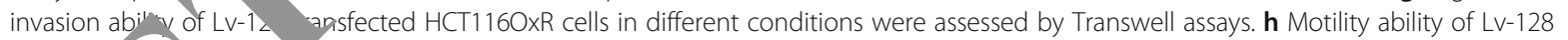
transfect d HCT1160xR dells in different conditions were assayed by wound healing assays. i Western blot analysis of protein MRP5 expression of LV-128. ffe H $^{\prime}$ CT1160xR cells in different conditions. $\mathbf{j}$ Accumulation of Pt in LV-128 transfected HCT1160xR cells in different conditions follaning en ure 30 MM, 24 h oxaliplatin treatment. k Total Pt-DNA adduct levels in Lv-128 transfected HCT1160xR cells in different conditions 1ollo ig expo re to $30 \mu \mathrm{M}, 24 \mathrm{~h}$ oxaliplatin treatment. I Immunofluorescence analysis of nuclear foci for $\mathrm{Y}-\mathrm{H}_{2} \mathrm{AX}$ expression of LV-128 transfected TT Gells in different conditions after $24 \mathrm{~h}$ oxaliplatin exposure $(30 \mu \mathrm{M})$. Scale bars, $10 \mu \mathrm{m}$. $\mathbf{m}$ Western blot analysis of protein Bmi 1 and MRP5 e, ssion in HCT1160xR cells after incubated with indicated factors. $\mathbf{n}$ Immunohistochemistry analysis of Bmi1 and MRP5 protein levels in xenograft tumy issues with intratumoral injection of NC-exo and 128-exo (20X). Results are presented as mean \pm SD. ${ }^{*} P<0.05$, ${ }^{* *} P<0.01$, ${ }^{* * *} P<0.001$

response by competitively binding Bmi1 and MRP5 mRNA 3'-UTR, leading to the mesenchymal-epithelial transition of oxaliplatin-resistant CRC cells and reduced cellular oxaliplatin efflux. We also demonstrated a novel strategy to increase CRC chemosensitivity using exosomes to transfer therapeutic miR-128-3p into resistant CRC cells. The miR-128-3p modified FHC cells effectively packages miR-128-3p into secreted exosomes, and mediates miR-128-3p transfer to oxaliplatin-resistant CRC cells. Consequently rendering resistant CRC cells more sensitive to chemotherapeutic agents by altering Bmi1 and MRP5 expression (Fig. 7). 


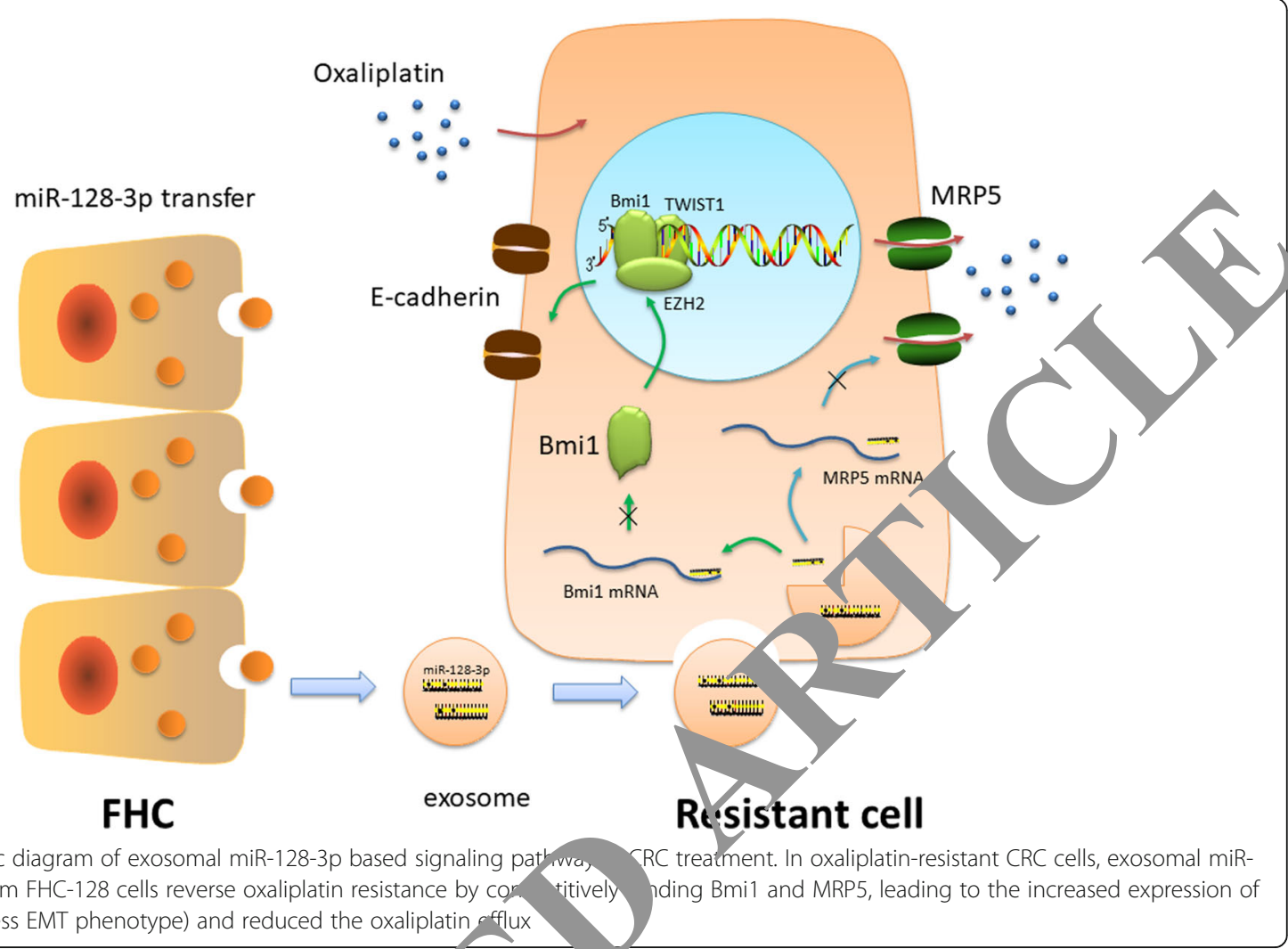

Mir-128 has been described as a tumor supp cosor, d a reduced level of miR-128 was first identified glioblas oma [33]. Recent studies suggested that verrant miR-128-3p expression has been obser red in some, nalignant cancer cell phenotypes such as: \& If-renewal, proliferation, apoptosis, cell motility, and in ion $11,34,35]$. Here, we extend the current 1 wledge by highlighting the role of miR-128-3p in chernor py-resistant CRC. Our results demonstron that miR-128-3p expression levels in CRC tumo issu and/cell lines were significantly lower than narm. tissues and cell lines. Additionally, downreo, a mi 128-3p was identified in oxaliplatin-resistan ells compared with sensitive cells. Therefor , we specul, ce that miR-128-3p might play importano in o raliplatin-resistant CRC.

I - dersta ing the mechanisms of drug resistance in $\mathrm{RC}$ essen al for optimizing current therapeutic strates wexplored the potential mechanisms underlying mik 3 -3p mediated reversal of chemoresistance by focusing on likely molecular targets. Here, we identified polycomb group protein Bmi1 as a functional target of miR-128-3p to regulate EMT. Previous studies have shown that downregulation of Bmil could restrain cell proliferation, arrest cell cycle, promote cell apoptosis, and inhibit cell self-renewal which is essential for CRC initiating cells [36]. In our previous study, Bmil is highly expressed in CRC and is a potential biomarker for diagnosis and prognosis [37]. Consistent with the observations that Bmi1 is essential in Twist1-induced epithelial-mesenchymal transition through repressed expression of E-cadherin in head and neck squamous cell carcinoma [30], our study found that miR-128-3p positively regulated E-cadherin expression in CRC cells through binding the Bmi1 $3^{`}$-UTR. Therefore, Bmi1 overexpression due to reduced miR-128-3p may result in chemotherapy-induced EMT in CRC via this pathway. Additionally, we found that MRP5 (also known as $\mathrm{ABCC}$ ), a member of the $\mathrm{ABC}$ transporter family, was also a target of miR-128-3p. The human ABC genes encode ATP-dependent transporters that can move substrates, against their electrochemical gradient, in both directions across biological membranes (cell and vesicles) [38]. Accumulating evidence suggests that increased MRP5 expression is associated with exposure to platinum drugs in lung cancer in vivo and/or the chronic stress response to xenobiotics [39]. Increased resistance to platinum drugs with elevated MRP5 levels may be due to glutathione S-platinum complex efflux. Our findings provide evidence that highly expressed miR-128-3p reduce oxaliplatin export by down-regulating MRP5 expression in cancer cells. Moreover, decreased oxaliplatin efflux could result in higher tissue distribution and intracellular drug localization to form damaging DNA-platinum adducts that ultimately destroy tumor 
cells. In short, our results demonstrate that compared with parent cells, miR-128-3p expression was significantly downregulated in oxaliplatin-resistant cells. Overexpression of miR-128-3p could reestablish sensitivity in resistant cells by reducing Bmi1 and MRP5 expression which related to oxaliplatin-resistance. Oxaliplatin combined with miR-128-3p overexpression inhibited the development of resistant CRC cells more effectively than oxaliplatin alone in vitro and in vivo.

Oxaliplatin therapy might have unrealized clinical benefits in the selection of oxaliplatin-responsive CRC patients that are masked due to a lack of biomarkers. Therefore, the identification of reliable predictive biomarkers for clinical benefits of oxaliplatin therapy is urgently needed. Ideal biomarkers, like microRNAs, are advantageous because they are more stable than other biological macromolecules. Herein, we performed the first investigation into the prognostic value of miR-128-3p for CRC oxaliplatin-resistance. Our results showed that lower miR-128-3p expression in pre-therapy CRC tumors significantly correlates with a poor oxaliplatin response. Moreover, our results demonstrated that miR-128-3p effectively distinguished resistant patients from sensitive patients, with a significantly higher AUC value of 0.868 , as well as a sensitivity or $65.0 \%$ and specificity of $91.4 \%$ at optimal cut-off valye of 0.227. We also estimated the prognostic po f miR-128-3p through Kaplan-Meier survival an arysis. tients with high miR-128-3p expression e\% ited dra matic improved prognosis following $o$ 'iplatin treatment. Taking this further, univar ate and mu, avariate Cox model analyses showed that niR-128 3p was an independent prognostic factor. The re, when determining a course of treatme we aavise evaluating miR-128-3p expression in $\mathrm{CRC}$ t/m $\mathrm{s}$ to predict patients who might ben from oxaliplatin therapy. In treatment-naive pati s h low miR-128-3p levels, we suggest therapeut to rease miR-128-3p expression as we found th. nhances esponse to oxaliplatin.

It is very impo t to contrast exogenous synthetic siRNAs vith microly, As which are endogenous molecules in al cells with potentially fewer unexpected off - net noing effects [40,41]. Since a microRNA olec le tarsets a set of coding genes, rather than a sing onc, therapies based on microRNA interference coul more potent in cancer treatment by targeting multiple molecular pathways. Exosomes have the capacity to protect cellular contents like miRNAs [42] from degradation in circulation and function as carriers to transmit their donor cells' contents to recipient cells [43]. Although liposomes may also offer advantages for therapeutic molecule delivery over viral-based delivery systems, they exhibit low efficiency and rapid clearance from the circulation [44]. Unlike liposomes, exosomes contain membrane anchored and transmembrane proteins that functionally enhance endocytosis, thus promoting the delivery of their internal content $[45,46]$. Exosomal proteins, such as CD47, allows for evasion from phagocytosis by the circulating monocytes and increases exosomes half-life in the circulation [47 48]. Moreover, recent evidence suggest that exosom $s$ exhibit a superior ability to deliver "drugs" and suppre amor growth when compared to liposomes [49]. In ade h, using exosomes might also minimize otoxic efrects when synthetic nanoparticles were used vi o [50]. Meanwhile, because of their $n$ hosize, excomes are explored as nanodevices for the development of new therapeutic applications. Mes hyi. uem cell-derived exosomes containing the po rug 5-fluorocytosine (5-FC) were internal; $2 \mathrm{e}$ by recipent tumor cells. The endocytosed exosomes $t$ tively triggered a dosedependent tum or 11 deatb following the intracellular conversion or 5 -FC to 5-fluorouracil [51]. Hence, natural ex mes are of considerable interest because the be u.ed as biological delivery vehicles for targeted tum or nerapy [52, 53]. In this study, we demonstrated a novel strategy for increasing CRC chemosenSIL through 128-exo mediated transfer of therapeutic miR- 8-3p. Our work shows that exosomes derived n miR-128-3p overexpressing FHC can deliver m) $R-128-3 p$ into oxaliplatin-resistant CRC cells in vitro and in vivo, further restoring CRC cell sensitivity to chemotherapeutic agents by altering the expression of target genes Bmi1 and MRP5 in resistant cells. Therefore, by decreasing the expression of target genes, exosomes from miR-128-3p-modified FHCs can effectively increase the chemo-sensitivity of CRC cells through the suppression of EMT and drug efflux. Given that systemic therapy with oxaliplatin is the standard of care for advanced-stage CRC [54], we further tested whether 128-exo can exert its inhibitory function in a mouse model. A lower concentration of oxaliplatin $\left(90 \mathrm{mg} / \mathrm{m}^{2}\right)$ than the clinical amount was used to treat CRC xenograft tumors. Immunohistochemistry assay results demonstrated that intra-tumor injection of 128-exo significantly enhanced the tumor suppression at lower oxaliplatin concentrations through decreased expression of Bmil and MRP5. Additionally, in vitro experiments indicated 128-exo treatment reduced gene expression in CRC cells over time, up to ten days after 128-exo treatment.

\section{Conclusion}

Our findings demonstrate that miR-128-3p acts not only as a clinical biomarker for oxaliplatin response but also as a therapeutic target. miR-128-3p delivery via exosomes increases the sensitivity of CRC cells to oxaliplatin, thereby providing a new treatment strategy for CRC. 


\section{Additional files}

Additional file 1: Table S1. Clinical characteristics of CRC patients in training phase. (DOCX $19 \mathrm{~kb}$ )

Additional file 2: Table S3. Clinical characteristics of 122 CRC patients in indicated groups. (DOCX $16 \mathrm{~kb}$ )

Additional file 3: Table S2. Primer sequence and antibody. (DOCX $18 \mathrm{~kb}$ ) Additional file 4: Figure S1. related to Fig. 2. miR-128-3p expression in CRC cell lines and its effect on oxaliplatin resistance. A. CCK8 assay of seven CRC cell lines (LoVo, HT29, SW480, SW620, HCT116, SW1116 and (aco2) followed by oxaliplatin treatment at indicated concentrations. B. A representative scatter-gram of Annexin V/PI potential test for parent and resistant cell apoptosis. C. RT-qPCR assay was performed to detect the miR-128-3p expression in seven CRC cell lines (LoVo, HT29, SW480, SW620, HCT116, SW1116 and (aco2) and normal FHC cells. D. RT-qPCR assay was performed to detect miR-128-3p expression in HT290xR cells transfected with lenti-miR-128-3p (Lv-128) and lenti-negative control (Ctrl). E. CCK8 assay of HT290xR cells transfected with LV-128 and Ctrl with oxaliplatin treatment at indicated concentrations. F. Flow cytometry apoptosis assay of HT290xR cells transfected with LV-128 and Ctrl with oxaliplatin treatment $(30 \mu \mathrm{M})$ for $24 \mathrm{~h}$. G. A representative scatter-gram of Annexin V/PI potential test for HCT1160xR (upper) and HT290xR (lower) cell apoptosis. H. RT-qPCR analysis of E-cadherin (E-cad), N-cadherin ( $\mathrm{N}$ cad), vimentin (Vim), and fibronectin (Fn) expression in HCT1160xR cells transfected with Lv-128 and Ctrl. I. RT-qPCR analysis of E-cad, N-cad, Vim, and Fn expression in HT290xR cells transfected with LV-128 and Ctrl. J. Western blot analysis of E-cad, N-cad, Vim, and Fn expression in HT290xR cells transfected with LV-128 and Ctrl. (TIF $1091 \mathrm{~kb}$ )

Additional file 5: Figure S2. related to Fig. 2. miR-128-3p expression in CRC cell lines and its effect on oxaliplatin resistance. A. Migration and invasion ability of HT290xR cells transfected with Lv-128 and Ctrl were assessed with a Transwell assay. B. Motility ability of HT290xR cells tran fected with LV-128 and Ctrl were assessed by wound healing assays Accumulation of Pt in HT290xR cells transfected with LV-128 or $\mathrm{C}$ following exposure to $30 \mu \mathrm{M}$ oxaliplatin treatment for $24 \mathrm{~h}$. D. Pt-DNA adduct levels in HT290xR cells transfected with Lv- ${ }^{2}$ or Ctr duced by oxaliplatin in HT290xR cells transfected vith LV-128 or C, after 24 h' oxaliplatin exposure $(30 \mu \mathrm{M})$. Scale bars, $10 \mathrm{~m}$. F. RT-qPCR assay was performed to detect the miR-128-3p expres $n$ in FHC cells transfected with Lv-128 or Ctrl. (TIF 1535 kb)

Additional file 6: Figure S3. related to Intercellular transfer of miR-128-3p by 128-Exo sensitized CRC cel's to ätin agents. A. Internalization of exosomes deriund from $\mathrm{A}-128$ cells. Labelled 128-exo (green fluorescent dye, PKHG ) wo uptake by HCT1160xR (DAPIlabelled) cells. B. RT-qPCR a sis 12,8 -3p in HT290xR cells preincubated with indicat fact c. CCno assay of HT290xR cells preincubated with indi ted factors $18 \mathrm{~h}$ followed by oxaliplatin treatment at ind ate ncentrations. D. Flow cytometry apoptosis assay of HT290xR colls pre-in ted with indicated factors for $48 \mathrm{~h}$ followed by oxalipla 4 treatment ( $3 \mathrm{a}$ a M) for $24 \mathrm{~h}$. E. A representative scatter-gram of Anne V/A potential test for HCT1160xR (upper) and HT290xR (lower) cen sptosis . Exosomes were imaged using electron m opy. bar $=200 \mathrm{~nm}$. G. RT-qPCR assay was performed to detec niR-128-p expression in HCT1160xR cells following various CCK8 assay of HCT1160xR cells pre-incubated with in ted factors for $48 \mathrm{~h}$ followed by oxaliplatin treatment at indicated conc rations. (TIF $1395 \mathrm{~kb}$ )

Additional file 7: Figure S4. related to Fig. 5. Intercellular transfer of miR-128-3p by 128-Exo sensitized CRC cells to oxaliplatin agents. A RT-qPCR analysis of E-cad, N-cad, Vim, and Fn mRNA expression in HCT1160xR cells after incubated with indicated factors for $48 \mathrm{~h}$. B. RTqPCR analysis of E-cad, N-cad, Vim, and Fn mRNA expression in HT290xR cells after incubated with indicated factors for $48 \mathrm{~h}$. C. Western blot analysis of protein E-cad, N-cad, Vim, and Fn expression in HT29OxR cells after incubated with indicated factors for $48 \mathrm{~h}$. D. Migration and invasion ability of HT290xR cells after incubated with indicated factors for $48 \mathrm{~h}$ were assessed by Transwell assays. E. Motility ability of HT290xR cells after incubated with indicated factors for $48 \mathrm{~h}$ were assayed by wound healing assays. F. Accumulation of Pt in HT290xR cells after incubated with indicated factors for $48 \mathrm{~h}$ followed by exposure to $30 \mu \mathrm{M}, 24 \mathrm{~h}$ oxaliplatin treatment. F. Total Pt-DNA adduct levels in HT290xR cells after incubated with indicated factors for $48 \mathrm{~h}$ following exposure to $30 \mu \mathrm{M}, 24 \mathrm{~h}$ oxaliplatin treatment. (TIF 1549 kb)

Additional file 8: Figure S5. related to Fig. 5. Intercellular tran sier of miR-128-3p by 128-Exo sensitized CRC cells to oxaliplatin age immunofluorescence analysis of nuclear foci for $\gamma-\mathrm{H}_{2} \mathrm{AX}$ expressic HT290xR cells after incubated with indicated factors for $48 \mathrm{~h}$ follow $24 \mathrm{~h}$ oxaliplatin exposure $(30 \mu \mathrm{M})$. B. HCT1160xR cell ve incubded with PBS, NC-exo and 128-exo for $48 \mathrm{~h}$ and replared w. kesh cu cure medium. The oxaliplatin IC50 at subsequent 0 day, 5 day ar 10 day were determined by CCK8 assay. C. RT-qPCR analy is of miR-128-3, in xenograft tissues after incubated with inc ted factor. (TIF 602 kb)

Additional file 9: Figure S6. relater Fig. ros containing miR-128-3p sensitized CRC cells t pxali $n$ by targeting to Bmi1 and MRP5. Luciferase activity assav as perform $f_{g}$ the cells co-transfected with pmiR-REPORT ${ }^{\mathrm{M}}$ vector $\mathrm{CO}$. ving Bmi2 wt 3'-UTR/Bmi1-mut 3'-UTR sequences (A) or MRP5-wt S'-UTR, 5-mut 3'-UTR sequences (B) and miR-128-3p mimics. $D$ re prent, as normalized fold change in luciferase activity. -qPC assay was performed to detect the Bmi1 mRNA (C) and MRi kpression in resistant cells transfected with LV-128 and Ctrl. expression $\mathrm{HCT} 1160 \times$, nd HT290xR cells transfected with LV-128 and Ctrl. F. CCK 8 as $\quad 128$ transfected HT290xR cells treated with indicated fac or, for $-8 \mathrm{~h}$ followed by oxaliplatin treatment at indicated concentration. G. Flow cytometry for apoptosis assay of Lv-128 fected HT) $90 \times R$ cells treated with indicated factors for $48 \mathrm{~h}$ foll d by oxaliplatin treatment $(30 \mu \mathrm{M})$ for $24 \mathrm{~h}$. H. A representative scatte gram of Annexin V/PI potential test for HCT1160xR (upper) and XR (lower) cell apoptosis. (TIF $1078 \mathrm{~kb}$ )

A ditional file 10: Figure S7. related to Fig. 6. Exosomes containing miR-128-3p sensitized CRC cells to oxaliplatin by targeting to Bmi1 and MRP5. A. Western blot analysis of Bmi1 and E-cad, N-cad, Vim, and Fn protein expression of LV-128 transfected HT290xR cells in different conditions. B. Migration and invasion ability of LV-128 transfected HT290xR cells in different conditions were assessed by Transwell assays. C. Motility ability of LV-128 transfected HT290xR cells in different conditions were assayed by wound healing assays. D. Western blot analysis of protein MRP5 expression of LV-128 transfected HT29OxR cells in different conditions. E. Accumulation of Pt in lenti-miR-128-3p transfected HT290xR cells in different conditions following exposure to oxaliplatin treatment $30 \mu \mathrm{M}$ for $24 \mathrm{~h}$. F. Total Pt-DNA adduct levels in LV128 transfected HT290xR cells in different conditions following exposure to $30 \mu \mathrm{M}, 24 \mathrm{~h}$ oxaliplatin treatment. G. Western blot analysis of $\mathrm{\gamma}-\mathrm{H}_{2} \mathrm{AX}$ expression in Lv-128 transfected HT290xR cells in different conditions 24 h after oxaliplatin exposure $(30 \mu \mathrm{M})$. H. Western blot analysis of Bmi1 and MRP5 protein expression in HT290xR cells after incubation with indicated factors. (TIF $1843 \mathrm{~kb}$ )

\section{Abbreviations}

128-exo: Lenti-miR-128-3p transfected FHC cells derived exosomes; AAS: Atomic absorption spectrophotometry; AUC: Area under the receiveroperating characteristic curve; Bmi1: B-cell-specific moloney murine leukemia virus integration site 1; CRC: Colorectal cancer; FHC-128: Lenti-miR-128-3p transfected FHC cells; FHC-NC: Lenti-NC transfected FHC cells; IHC: Immunohistochemistry; Iv-128: Lentiviral vector miR-128-3p; IvNC: Lentiviral vector negative control; MRP5: Multidrug resistant protein 5; NC-exo: Lenti-NC transfected FHC cells derived exosomes; NTA: Nanoparticle tracking analysis; PFS: Progression-free survival; ROC: Receiver operating characteristic; RT-qPCR: Quantitive real-time polymerase chain reaction; TEM: Transmission electron microscopy; TNM: Tumor-node metastasis

\section{Acknowledgements}

We thank Dr. Chengjun Zhou (Department of Pathology, The Second Hospital of Shandong University) and Dr. Junhui Zhen (Department of 
Pathology, Qilu Hospital of Shandong University) for their assistance in cytology and histology evaluations.

\section{Funding}

This work was supported by grant from the Natural Science Foundation of China (81472025 and 81772271), Shandong Technological Development Project (2016CYJS01A02), The Science and Technology Development Plan Project of Jinan (201602154), Taishan Scholar Program of Shandong Province, the Natural Science Foundation of Shandong Province (ZR2017ZB0419), The Fundamental Research Funds of Shandong University (2017BTS01, 2018JC002 and 2017JC031), Outstanding young scientist research award fund of Shandong Province (BS2014YY002).

\section{Availability of data and materials}

The datasets used and/or analyzed during the current study are available within the manuscript and its supplementary information files.

\section{Authors' contributions}

$T L, X Z, L T D, Y S W$ and $C X W$ contributed to the design of the study. TL, XZ, YHZ and ZWS performed the experiments. TL, PLL, LLW and CXW contributed to the writing and revision of the manuscript. TL, XML, WLD, YJX and HT contributed to the material support of the study. All authors read and approved the final manuscript.

\section{Ethics approval and consent to participate}

This study was reviewed and approved by the Ethics Committee of The Second Hospital of Shandong University, the Ethics Committee of Qilu Hospital of Shandong University and the Ethics Committee of Shandong Provincial Traditional Chinese Medical Hospital, and all the participants signed an informed consent form.

\section{Consent for publication}

All the patients involved in our study obtained written consent for publication.

\section{Competing interests}

The authors declare that they have no competing interests.

\section{Publisher's Note}

Springer Nature remains neutral with regard to juris ctional claims in published maps and institutional affiliations.

\section{Author details}

${ }^{1}$ Department of Clinical Laboratory, The Se University, No. 247 Beiyuan Street, Jinan 250037, Cm, a. ${ }^{2}$ Department of Clinical Laboratory, Qilu Hospital dong (niversity, Jinan 250012, Shandong Province, China. ${ }^{3} \mathrm{D}$ bartn $\mathrm{nt}$ of $\mathrm{Pr}$ Jentive Medicine, Shandong Provincial Traditional Chinese di_al, Jinan 250012, People's Republic of China. ${ }^{4}$ Car cer Eente ilu Hospital, Shandong University, Jinan 250012, Shandong P. Cere, China. epartment of Surgery, The Affiliated Hospital of Medic. Coli Qingdab University, Qingdao 266071, Shandong Province,

Received. Oc ber 2018 Accepted: 25 February 2019

Publiched o, 16 March 2019 rics. CA Cancer J Clin. 2011;61:69-90.

2. Ya, g AD, Fan F, Camp ER, van Buren G, Liu W, Somcio R, Gray MJ, Cheng H, Hoff PM, Ellis LM. Chronic oxaliplatin resistance induces epithelial-tomesenchymal transition in colorectal cancer cell lines. Clin Cancer Res. 2006; 12:4147-53.

3. Arango D, Wilson AJ, Shi Q, Corner GA, Aranes MJ, Nicholas C, Lesser M, Mariadason JM, Augenlicht LH. Molecular mechanisms of action and prediction of response to oxaliplatin in colorectal cancer cells. Br J Cancer. 2004;91:1931-46.

4. Meads MB, Gatenby RA, Dalton WS. Environment-mediated drug resistance: a major contributor to minimal residual disease. Nat Rev Cancer. 2009;9: 665-74.
5. Li H, Yang BB. Friend or foe: the role of microRNA in chemotherapy resistance. Acta Pharmacol Sin. 2013;34:870-9.

6. Holzel M, Bovier A, Tuting T. Plasticity of tumour and immune cells: a source of heterogeneity and a cause for therapy resistance? Nat Rev Cancer. 2013; 13:365-76.

7. McMillin DW, Negri JM, Mitsiades CS. The role of tumour-stromal interactions in modifying drug response: challenges and opportunities. Nat Rev Drug Discov. 2013;12:217-28.

8. Breunig C, Erdem N, Bott A, Greiwe JF, Reinz E, Bernhardt S, Gir omêli C, Wachter A, Kanthelhardt EJ, Beissbarth T, et al. TGFbeta1 regula induced cell migration and hepatocyte growth factor receptor $\mathrm{Mt}$ expression via C-ets-1 and miR-128-3p in basal-like br ast cancer. Mo Oncol. 2018;12:1447-63.

9. Ambs S, Prueitt RL, Yi M, Hudson RS, Howe TM Nocca Vallas TA, Liu CG, Volinia S, Calin GA, et al. Genomic profil ig of microRN, ad messenger RNA reveals deregulated microRNA expres $n$ in prostate cancer. Cancer Res. 2008;68:6162-70.

10. Khan AP, Poisson LM, Bhat VB, Fern, Zhà ana-Sundaram S, Michailidis G, Nesvizhskii Al, Or.n GS, innaiyan AM, Sreekumar A. Quantitative proteomic profi q of prosta. Kcer reveals a role for miR128 in prostate cancer. Nol Co oteomics 2010;9:298-312.

11. Cai J, Fang L, Huang Y, Li R, Xu $\lambda$, Z, Zhang L, Yang Y, Zhu X, Zhang $H$, et al. Simultaneour ctivation o, $N$ nt/beta-catenin and TGFbeta signalling by $m$ 128-3 confers chemoresistance-associated metastasis in NSCLC. Nat Comi curn. 870.

12. Xiao M, Lou C, Xiao ang Y, Cai X, Li C, Jia S, Huang Y. MiR-128 regulatic falucose $n$-abolism and cell proliferation in triple-negative breast cal can ang. 2018;105:75-85.

13. Shan ZN, Tiz R, Znang M, Gui ZH, Wu J, Ding M, Zhou XF, He J. miR128-1 inhibits the arowth of glioblastoma multiforme and glioma stem-like cells targeting BMI1 and E2F3. Oncotarget. 2016;7:78813-26.

14. $-T$, Wang $Y W$, Xing AY, Shi DB, Zhang H, Guo XY, Xu J, Gao P. $\operatorname{Pr}$ nostic value of microRNA signature in patients with gastric cancers. Sci 2017:7:42806

15. Lian B, Yang D, Liu Y, Shi G, Li J, Yan X, Jin K, Liu X, Zhao J, Shang W. Zhang R: miR-128 targets the SIRT1/ROS/DR5 pathway to sensitize colorectal Cancer to TRAlL-induced apoptosis. Cell Physiol Biochem. 2018;49:2151-62.

16. Sun Z, Shi K, Yang S, Liu J, Zhou Q, Wang G, Song J, Li Z, Zhang Z, Yuan W. Effect of exosomal miRNA on cancer biology and clinical applications. Mol Cancer. 2018;17:147.

17. Gonzalez-Begne M, Lu B, Han X, Hagen FK, Hand AR, Melvin JE, Yates JR. Proteomic analysis of human parotid gland exosomes by multidimensional protein identification technology (MudPIT). J Proteome Res. 2009;8:1304-14.

18. Cheshomi H, Matin MM. Exosomes and their importance in metastasis, diagnosis, and therapy of colorectal cancer. J Cell Biochem. 2018. https:// doi.org/10.1002/jcb.27582.

19. $\mathrm{Hu} \mathrm{G}$, Drescher KM, Chen XM. Exosomal miRNAs: biological properties and therapeutic potential. Front Genet. 2012;3:56.

20. Katakowski M, Buller B, Zheng X, Lu Y, Rogers T, Osobamiro O, Shu W, Jiang F, Chopp M. Exosomes from marrow stromal cells expressing miR-146b inhibit glioma growth. Cancer Lett. 2013;335:201-4.

21. Li $P$, Zhang $X$, Wang $H$, Wang L, Liu T, Du L, Yang Y, Wang C. MALAT1 is associated with poor response to Oxaliplatin-based chemotherapy in colorectal Cancer patients and promotes Chemoresistance through EZH2. Mol Cancer Ther. 2017;16:739-51.

22. Qu L, Ding J, Chen C, Wu ZJ, Liu B, Gao Y, Chen W, Liu F, Sun W, Li XF, et al. Exosome-transmitted IncARSR promotes Sunitinib resistance in renal Cancer by acting as a competing endogenous RNA. Cancer Cell. 2016;29:653-68.

23. Eisenhauer EA, Therasse P, Bogaerts J, Schwartz LH, Sargent D, Ford R, Dancey J, Arbuck S, Gwyther S, Mooney M, et al. New response evaluation criteria in solid tumours: revised RECIST guideline (version 1.1). Eur J Cancer. 2009;45:228-47.

24. Thery C, Amigorena S, Raposo G, Clayton A. Isolation and characterization of exosomes from cell culture supernatants and biological fluids. Curr Protoc Cell Biol. 2006;30:3-22.

25. Zhou W, Fong MY, Min Y, Somlo G, Liu L, Palomares MR, Yu Y, Chow A, O'Connor ST, Chin AR, et al. Cancer-secreted miR-105 destroys vascular endothelial barriers to promote metastasis. Cancer Cell. 2014;25:501-15.

26. Alvarez-Erviti L, Seow Y, Yin H, Betts C, Lakhal S, Wood MJ. Delivery of siRNA to the mouse brain by systemic injection of targeted exosomes. Nat Biotechnol. 2011;29:341-5. 
27. Tian Y, Li S, Song J, Ji T, Zhu M, Anderson GJ, Wei J, Nie G. A doxorubicin delivery platform using engineered natural membrane vesicle exosomes for targeted tumor therapy. Biomaterials. 2014;35:2383-90.

28. Wu WJ, Zhang Y, Zeng ZL, Li XB, Hu KS, Luo HY, Yang J, Huang P, Xu RH. beta-phenylethyl isothiocyanate reverses platinum resistance by a GSHdependent mechanism in cancer cells with epithelial-mesenchymal transition phenotype. Biochem Pharmacol. 2013;85:486-96.

29. Fang T, Lv H, Lv G, Li T, Wang C, Han Q, Yu L, Su B, Guo L, Huang S, et al. Tumor-derived exosomal miR-1247-3p induces cancer-associated fibroblast activation to foster lung metastasis of liver cancer. Nat Commun. 2018;9:191.

30. Yang MH, Hsu DS, Wang HW, Wang HJ, Lan HY, Yang WH, Huang $\mathrm{CH}$, Kao SY, Tzeng CH, Tai SK, et al. Bmi1 is essential in Twist1-induced epithelialmesenchymal transition. Nat Cell Biol. 2010;12:982-92.

31. Wilson PM, Danenberg PV, Johnston PG, Lenz HJ, Ladner RD. Standing the test of time: targeting thymidylate biosynthesis in cancer therapy. Nat Rev Clin Oncol. 2014;11:282-98.

32. DeGorter MK, Xia CQ, Yang JJ, Kim RB. Drug transporters in drug efficacy and toxicity. Annu Rev Pharmacol Toxicol. 2012;52:249-73.

33. Ciafre SA, Galardi S, Mangiola A, Ferracin M, Liu CG, Sabatino G, Negrini M, Maira G, Croce CM, Farace MG. Extensive modulation of a set of microRNAs in primary glioblastoma. Biochem Biophys Res Commun. 2005;334:1351-8.

34. Santos MC, Tegge AN, Correa BR, Mahesula S, Kohnke LQ, Qiao M, Ferreira MA, Kokovay E, Penalva LO. miR-124, -128 , and -137 orchestrate neural differentiation by acting on overlapping gene sets containing a highly connected transcription factor network. Stem Cells. 2016;34:220-32.

35. Koh H, Park H, Chandimali N, Huynh DL, Zhang JJ, Ghosh M, Gera M, Kim N, Bak Y, Yoon DY, et al. MicroRNA-128 suppresses paclitaxel-resistant lung cancer by inhibiting MUC1-C and BMI-1 in cancer stem cells. Oncotarget. 2017:8:110540-51.

36. Kreso A, van Galen P, Pedley NM, Lima-Fernandes E, Frelin C, Davis T, Cao L, Baiazitov R, Du W, Sydorenko N, et al. Self-renewal as a therapeutic target in human colorectal cancer. Nat Med. 2014;20:29-36.

37. Zhang X, Yang X, Zhang Y, Liu X, Zheng G, Yang Y, Wang L, Du L, Wang C. Direct serum assay for cell-free bmi-1 mRNA and its potential diagnostic and prognostic value for colorectal cancer. Clin Cancer Res. 2015;21:1225_-

38. Nies AT, Magdy T, Schwab M, Zanger UM. Role of ABC transporters fluoropyrimidine-based chemotherapy response. Adv Cancer Res. 2015; 217-43.

39. Oguri T, Isobe T, Suzuki T, Nishio K, Fujiwara Y, Katoh , Increased expression of the MRP5 gene is associate th expost platinum drugs in lung cancer. Int J Cancer. 200 86:95-100.

40. Krutzfeldt J, Rajewsky N, Braich R, Rajeev KG, Tu I T, Manoh łran M, Stoffel M. Silencing of microRNAs in vivo with 'antagon Nature 2005:438:685-9.

41. Srinivasan S, Selvan ST, Archunan G, Gulvas B, Padim ran P. MicroRNAs -the next generation therapeutic target. man diseases. Theranostics. 2013:3:930-42.

42. Li Y, Zheng Q, Bao C, Li S, Gy Zhao J, hen D, Gu J, He X, Huang S. Circular RNA is enriched d stab in exos hes: a promising biomarker for cancer diagnosis. Cell Res. $15 \cdot$ ?

43. Zhang Y, Liu D, Chen $\lambda$, Li J, Bian Z, Sun F, Lu J, Yin Y, Cai $X$, et al. Secreted monos, miR-150 en, ices targeted endothelial cell migration. Mol Cell. 2016 39:15.

44. van der $M \quad R$, Fens M ader P, van Solinge WW, Eniola-Adefeso O, Schiffe ers RM. Extracellul, vesicles as drug delivery systems: lessons from the/ $m$ field. Y Control Release. 2014;195:72-85.

45. Vader $P$, FA, $P$, sterkamp G, Schiffelers RM. Extracellular vesicles for drug ery. Aa ag Deliv Rev. 2016;106:148-56.

con KB, Cudbergsson JM, Skov MN, Pilgaard L, Moos T, Duroux M. A isive overview of exosomes as drug delivery vehicles - endogenous carriers for targeted cancer therapy. Biochim Biophys Acta. 1846;2014:75-87.

7. Brovn EJ, Frazier WA. Integrin-associated protein (CD47) and its ligands. Trends Cell Biol. 2001;11:130-5.

48. Jaiswal S, Jamieson CH, Pang WW, Park CY, Chao MP, Majeti R, Traver D, van Rooijen N, Weissman IL. CD47 is upregulated on circulating hematopoietic stem cells and leukemia cells to avoid phagocytosis. Cell. 2009;138:271-85.

49. Kamerkar S, LeBleu VS, Sugimoto H, Yang S, Ruivo CF, Melo SA, Lee JJ, Kalluri R. Exosomes facilitate therapeutic targeting of oncogenic KRAS in pancreatic cancer. Nature. 2017;546:498-503.

50. Simoes S, Filipe A, Faneca H, Mano M, Penacho N, Duzgunes N, de Lima MP. Cationic liposomes for gene delivery. Expert Opin Drug Deliv. 2005;2: 237-54
51. Ursula A, Jana J, Katarina B, Petra P, Martin P, Pavel P, Ondrej T, Juraj K, Martina Z, Vanda R, Cestmir A. Prodrug suicide gene therapy for cancer targeted intracellular by mesenchymal stem cell exosomes. Int J Cancer. 2018. https://doi.org/10.1002/ijc.31792.

52. Zhang X, Yuan X, Shi H, Wu L, Qian H, Xu W. Exosomes in cancer: small particle, big player. J Hematol Oncol. 2015;8:83.

53. O'Loughlin AJ, Woffindale CA, Wood MJ. Exosomes and the emerging field of exosome-based gene therapy. Curr Gene Ther. 2012;12:262-74.

54. Meyerhardt JA, Mayer RJ. Systemic therapy for colorectal cance $\mathrm{N}$ Engl J Med. 2005;352:476-87.

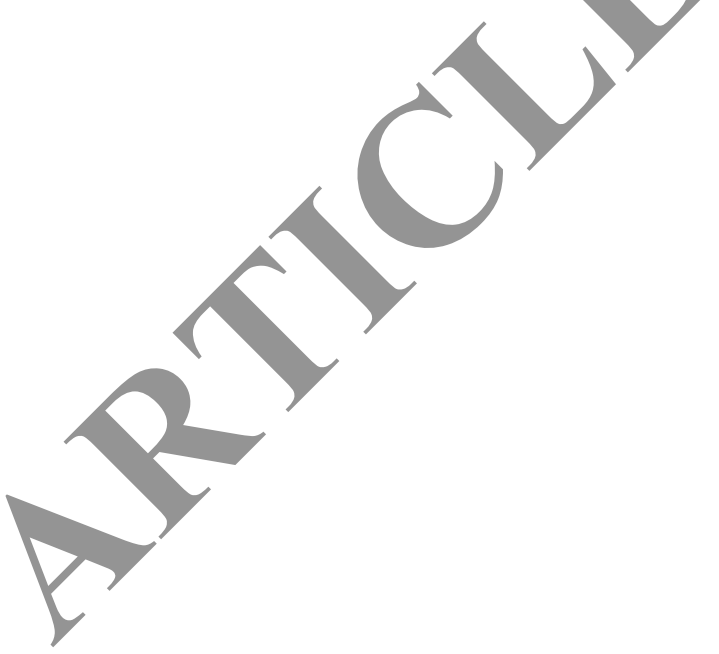

Ready to submit your research? Choose BMC and benefit from:

- fast, convenient online submission

- thorough peer review by experienced researchers in your field

- rapid publication on acceptance

- support for research data, including large and complex data types

- gold Open Access which fosters wider collaboration and increased citations

- maximum visibility for your research: over $100 \mathrm{M}$ website views per year

At BMC, research is always in progress.

Learn more biomedcentral.com/submissions 